\title{
RESEARCH
}

Open Access

\section{Role of NADPH oxidase- 2 in the progression of the inflammatory response secondary to striatum excitotoxic damage}

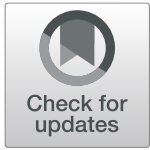

Diego Rolando Hernández-Espinosa, Lourdes Massieu, Teresa Montiel and Julio Morán * (D)

\begin{abstract}
Background: During excitotoxic damage, neuronal death results from the increase in intracellular calcium, the induction of oxidative stress, and a subsequent inflammatory response. NADPH oxidases (NOX) are relevant sources of reactive oxygen species (ROS) during excitotoxic damage. NADPH oxidase-2 (NOX-2) has been particularly related to neuronal damage and death, as well as to the resolution of the subsequent inflammatory response. As ROS are crucial components of the regulation of inflammatory response, in this work, we evaluated the role of NOX-2 in the progression of inflammation resulting from glutamate-induced excitotoxic damage of the striatum in an in vivo model.
\end{abstract}

Methods: The striata of wild-type C57BL/6 J and NOX-2 KO mice (gp91 Cybbtm1Din/J) were stereotactically injected with monosodium glutamate either alone or in combination with IL-4 or IL-10. The damage was evaluated in histological sections stained with cresyl violet and Fluoro-Jade B. The enzymatic activity of caspase-3 and NOX were also measured. Additionally, the cytokine profile was identified by ELISA and motor activity was verified by the tests of the cylinder, the adhesive tape removal, and the inverted grid.

Results: Our results show a neuroprotective effect in mice with a genetic inhibition of NOX-2, which is partially due to a differential response to excitotoxic damage, characterized by the production of anti-inflammatory cytokines. In NOX-2 $\mathrm{KO}$ animals, the excitotoxic condition increased the production of interleukin-4, which could contribute to the production of interleukin-10 that decreased neuronal apoptotic death and the magnitude of striatal injury. Treatment with interleukin-4 and interleukin-10 protected from excitotoxic damage in wild-type animals.

Conclusions: The release of proinflammatory cytokines during the excitotoxic event promotes an additional apoptotic death of neurons that survived the initial damage. During the subsequent inflammatory response to excitotoxic damage, ROS generated by NOX-2 play a decisive role in the extension of the lesion and consequently in the severity of the functional compromise, probably by regulating the anti-inflammatory cytokines production.

Keywords: NADPH oxidase, NOX-2, Glutamate, Excitotoxicity, Striatum, Caspase-3, Neuroinflammation, Interleukin-4, Interleukin-10

\footnotetext{
*Correspondence: jmoran@ifc.unam.mx

Instituto de Fisiología Celular, División de Neurociencias, Universidad

Nacional Autónoma de México (UNAM), Apartado Postal 70-253, 04510

Ciudad de México, Mexico
}

(c) The Author(s). 2019 Open Access This article is distributed under the terms of the Creative Commons Attribution 4.0 International License (http://creativecommons.org/licenses/by/4.0/), which permits unrestricted use, distribution, and reproduction in any medium, provided you give appropriate credit to the original author(s) and the source, provide a link to the Creative Commons license, and indicate if changes were made. The Creative Commons Public Domain Dedication waiver (http://creativecommons.org/publicdomain/zero/1.0/) applies to the data made available in this article, unless otherwise stated. 


\section{Background}

During excitotoxic damage, neuronal death produced by the overstimulation of the glutamate receptors is determined by several factors, including the increase of intracellular calcium [1], reactive oxygen species (ROS) production [2], microglia activation, and inflammatory responses [3]. Among these factors, the increase in ROS contributes significantly to the subsequent inflammatory process [4]. This condition has implications not only at the onset of damage, but also during the progression of the neuronal death [5].

Although the mitochondria have been classically considered as the main source of ROS [6], the relevance of other sources of ROS such as the NADPH oxidases family (NOX), which are widely distributed in all the studied species and are present in basically all the cell types evaluated, has gained great importance as mediators of excitotoxic damage [7]. In this regard, the genetic or pharmacological inhibition of NOX activity constitutes a neuroprotective condition in several pathologies involving excitotoxicity, such as hypoxia, hypoglycemia, and neuroinflammation [8-10]. Among the homologs of the NOX family, NOX-2 seems to be the main responsible for the observed neuronal death in numerous models of excitotoxic damage $[11,12]$. The specific inhibition of NOX-2 in neurons, astrocytes, and microglia prevents neuronal death in different experimental conditions $[13,14]$. In a previous study, we observed in genetically deficient NOX-2 mice and wild-type animals treated with a NOX inhibitor that ROS production, lesion size, and microglial reactivity were markedly decreased during excitotoxic damage [13].

A large body of evidence points to neuroinflammation as a main component of most of the central nervous system (CNS) disorders, including those involving excitotoxic damage [15]. Local immune cells orchestrate a series of events in order to stimulate tissue reparation in response to cell damage [16]. Microglia activation constitutes the first line of defense against brain tissue injury [17], through the induction of a range of phenotypes from resting ramified cells to motile amoeboid microglial cells [18]. At the molecular level, a variety of pro- and anti-inflammatory mediators, including interleukins, as well as ROS, nitric oxide, and eicosanoids are produced [19]. In contrast to proinflammatory mediators that participate in neuronal death, the anti-inflammatory mediators can contribute to neuroprotective actions [20,21].

Cytokines are pleiotropic molecules that define the characteristics and the resolution of the immune response [22]. The characteristics of the response are subordinated to the sum of the proinflammatory and anti-inflammatory stimuli in the microenvironment. TNF- $\alpha$, IL-1 $\beta$, IL-6, IL-8, and IL-12, among others, are considered as classic proinflammatory molecules [23-25], while TGF- $\beta$, IL-4, and IL-10 are classified as anti-inflammatory cytokines [26, 27].
A simplified classification of the polarization of microglia has been developed, and two phenotypes were proposed based on functional characteristics, the type of cytokines released, and the presence of some molecular markers [28]. The M1 phenotype refers to the classically activated macrophages, which is characterized by the expression of proinflammatory cytokines [29] and the M2 phenotype designates the alternatively activated macrophages that are related to the production of anti-inflammatory cytokines and the resolution of the process [30-32].

Although the M1/M2 concept is widely accepted, it should be noted that the new technologies and the recent data in the field have led to reconsider this classification. For example, both "M1" and "M2" markers can be simultaneously expressed in the same microglial cells or macrophages [33] and M2 cells show a wide range of functional and biochemical features [34]. Thus, the microglial/macrophage polarization seems to be a more complex process than originally described and the M1/ M2 phenotypic classification has been reviewed [35, 36], and different intermediate phenotypes have been described on the basis of their functionality and the molecular markers expressed under different physiological states [35, 37].

The mechanisms mediating the inflammatory response of macrophages/microglia are not completely understood, but evidence has provided a framework to propose that ROS may shape the inflammatory response [38, 39], as well as the regulation of microglial activation [40, 41]. This is in line with the association between ROS and several microglia-driven neuropathologies [38]. On the other hand, experimental evidence suggests that microglial NOX2 is involved in neurotoxicity by both producing extracellular ROS [41] and by participating in the redox signal involved in the inflammatory response [42, 43]. For example, NOX activation by interferon and LPS results in microglial expression of iNOS and cytokines mediated by the activation of MAP kinases, $\mathrm{NFkB}$, and STAT1 phosphorylation $[44,45]$.

It has been suggested that NOX2 plays a key role in the expression of the M1 phenotype by a mechanism mediated by IL10 and STAT3 [37, 46]. Furthermore, the lack of NOX2 leads to a M2 phenotype mediated by a downregulation of $N F \kappa B$ nuclear translocation in a model of TBI and diabetes [46, 47]. Thus, ROS derived from glial cells and from different sources, including NOX2, participate in the microglial activation and play a key action by defining the microglial phenotype, which may have a central role in neurotoxicity and neurodegenerative diseases $[43,45]$.

In this study, we evaluated the time course of cell damage, NOX activity, and production of cytokines, as well as the functional sequelae, resulting from the excitotoxic damage in an in vivo model. We also tested the 
protective action of two exogenous anti-inflammatory cytokines in this model. We propose that NOX-2, besides participating in the neuronal excitotoxic damage, also regulate the production of pro- and anti-inflammatory cytokines, which results critical for the progression of the cell death.

\section{Methods}

\section{Animals}

All animals were handled according to the National Institutes of Health Guide for the Care and Use of laboratory animals (NIH Publication No. 8023, revised 1978) and the local Committee for the Care and Use of Laboratory Animals (CICUAL protocol JMA72-15). All efforts were made to minimize pain, as well as the number of animals used. Wild-type (WT) adult mice C57BL/6 (8 weeks old) were obtained from the bioterium of the Instituto de Fisiología Celular, Universidad Nacional Autónoma de México. The NOX-2 KO (gp91 ${ }^{\mathrm{Cybbtm1Din/J}}$ ) adult mice generated on a C57BL/6 background were purchased from the Jackson Laboratory (Bar Harbor, ME), and the colony was established at the vivarium of the Instituto de Fisiología Celular, Universidad Nacional Autónoma de México. Mice were housed and kept under controlled temperature $\left(20-22^{\circ} \mathrm{C}\right)$ with a regulated 12-h light-dark cycle, with water and food ad libitum. The mice used for this study were divided as follows: 40 animals were used for histological analyses, 30 for immunoblot and enzyme activity determinations (NOX and caspase-3), and 30 for cytokine analysis.

\section{Intrastriatal glutamate injection}

C57BL/6 WT and NOX-2 KO mice were anesthetized with $3 \%$ isoflurane in a $95 \% \mathrm{O} 2 / 5 \% \mathrm{CO} 2$ mixture and placed on a stereotaxic frame (David Kopf Instruments, Tujunga, CA). A stainless steel needle was positioned in the right striatum according to the following coordinates: anterior-posterior $+0.8 \mathrm{~mm}$ from bregma, lateral $+2.2 \mathrm{~mm}$ from midline, and vertical $3.2 \mathrm{~mm}$ from dura [35]. With the aid of an injection pump (model 55; Harvard, South Natick, MA), $0.5 \mu \mathrm{L}$ of a solution of monosodium glutamate $(1 \mathrm{M})$ or saline solution $(0.9 \%)$ was injected $(0.175 \mu \mathrm{L} / \mathrm{min})$. A second (25 WT animals) and a third group (25 WT animals) of mice were treated with $0.7 \mathrm{ng} / \mathrm{mL}$ of interleukin-4 (cell signaling \#5208) or $0.4 \mathrm{ng} / \mathrm{mL}$ of interleukin-10 (cell signaling \#5261), respectively, in the same monosodium glutamate solution (Fig. 1). Five minutes after the injection, the needle was gently withdrawn, and the skin was sutured with nylon [48]. Mice recovered from anesthesia in a temperature-controlled chamber and were placed in individual cages with water and food ad libitum.

At different times after the surgery, animals received a lethal dose of sodium pentobarbital to subsequently extract the brain. For biochemical analyses, some animals were killed by cervical dislocation at different times ( 1 , 6,12 , and $24 \mathrm{~h}$ ) and striata were dissected and homogenized. To that, the olfactory bulb and cerebellum were removed from the brain and a sagittal section was made on the midline to separate the hemispheres and dissect the striate, which can be delimited as tissue slightly more transparent than the surrounding cortex [49]. The tissue obtained (15-20 mg) was homogenized in lysis buffer and protease inhibitors at $4{ }^{\circ} \mathrm{C}$ (OMNI TC homogenizer). The homogenate was centrifuged at $5000 \mathrm{~g}$ for $5 \mathrm{~min}$ to remove the cellular debris and subsequently the amount of protein was quantified [50].

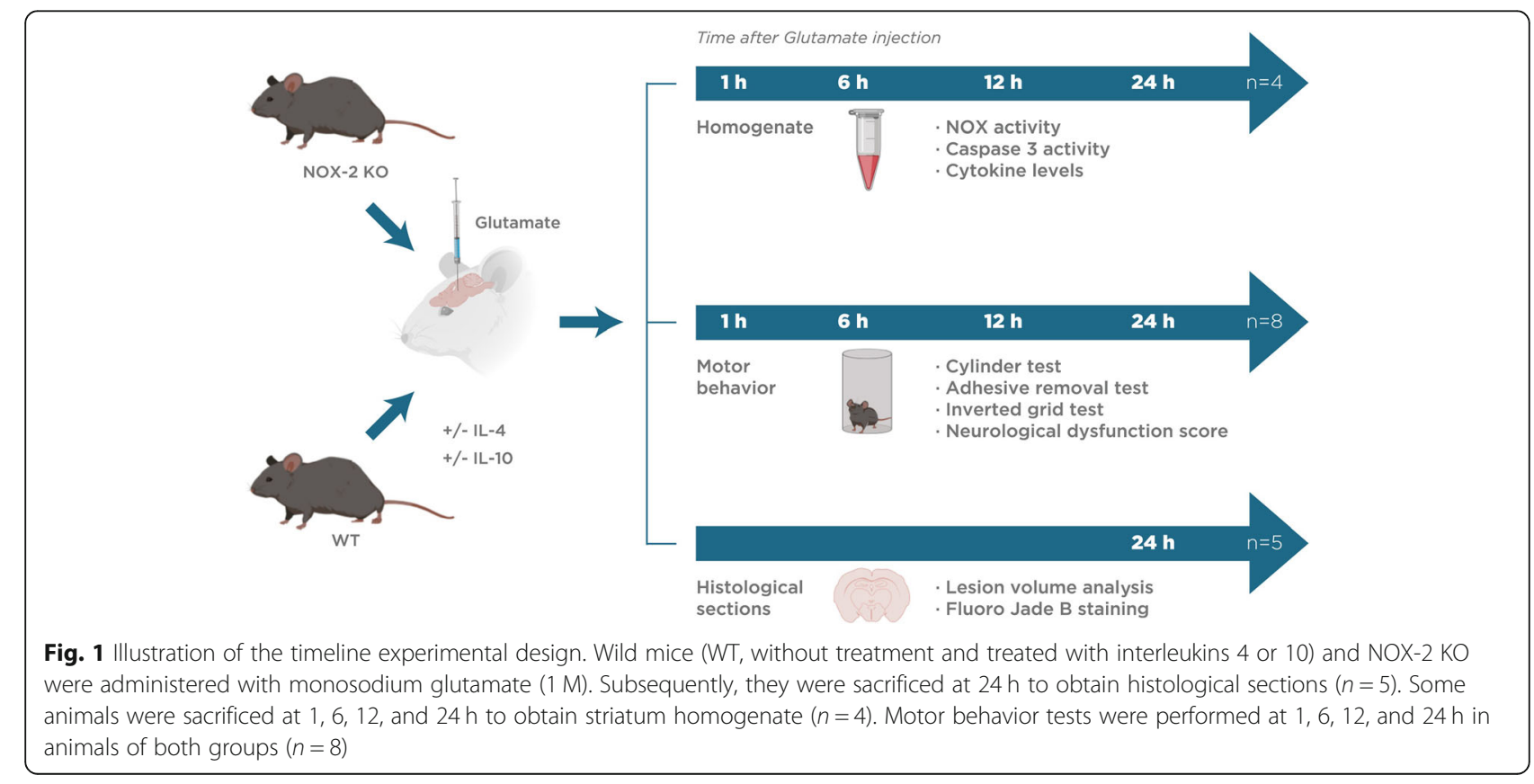




\section{Lesion volume analysis}

Glutamate-induced lesions were evaluated $24 \mathrm{~h}$ after the surgery (Fig. 1). Mice were deeply anesthetized with sodium pentobarbital and were transcardially perfused with $30 \mathrm{~mL}$ of $0.9 \%$ saline solution followed by $35 \mathrm{~mL}$ of $4 \%$ paraformaldehyde solution in $0.1 \mathrm{mM}$ phosphate buffer at $\mathrm{pH}$ 7.4. Brains were removed and placed in the same fixative solution at $4{ }^{\circ} \mathrm{C}$. Consecutive series of striatal coronal sections ( $40 \mu \mathrm{m}$ thick) for cresyl violet and Fluoro-Jade B (FJB; Chemicon, Temecula, CA) staining were obtained in a cryostat (1510s, Leica, Microsystems Nussloch GmbH, Heidelberger Nussloch, Germany). After staining with cresyl violet, all sections where a lesion was visible (pale cresyl violet stain) were selected for quantification of the lesion volume. The damaged areas were delineated manually and measured using an image analyzer (ImageJ 1.48v analyzer program; Wayne Rasband, NIH, USA) by an experimenter blinded to the treatments. Total lesion volume was obtained from the sum of all damaged areas multiplied by the width of the sections $(40 \mu \mathrm{m})$.

\section{Fluoro-Jade B staining}

Briefly, one drop of $1 \% \mathrm{NaOH}$ solution diluted in $80 \%$ ethanol was added to coronal sections mounted on slides, and after $2 \mathrm{~min}$, it was replaced by a 70\% ethanol solution. Slides were covered with $0.06 \%$ potassium permanganate for $10 \mathrm{~min}$, and then brain sections were washed and incubated for $10 \mathrm{~min}$ with a $0.0004 \%$ Fluoro-Jade B (FJB) solution prepared in $0.1 \%$ acetic acid. Finally, the sections were washed, dried at $50^{\circ} \mathrm{C}$, dehydrated with xylol, and covered with Permount (Fisher Scientific, Fair Lawn, NJ). Slices were observed under an epi-fluorescence microscope (Eclipse Ti-S, Nikon instruments Inc.) using a U-MNB2 filter $(395-590 \mathrm{~nm})$. Total FJB-positive cells were counted as previously described using the ImageJ.1.48v analyzer program (Wayne Rasband, NIH, USA) in the entire striatum in three sections per mouse, namely, the section containing the needle tract (middle section) and the adjacent anterior and posterior sections located $160 \mu \mathrm{m}$ away from the middle section [48].

\section{NOX activity}

NOX activity was determined in striatal homogenates at different times $(0.5,1,3,6,12$, and $24 \mathrm{~h})$ after glutamate administration (Fig. 1). NOX activity was estimated as the oxidation of dihydroethidium (DHE) to ethidium (Et) [48]. Briefly, tissue homogenates were incubated with $0.02 \mathrm{mM}$ DHE, $0.5 \mathrm{mg} / \mathrm{mL}$ salmon DNA, and $0.2 \mathrm{mM} \mathrm{NADPH}$ as substrate. Et fluorescence was measured during $30 \mathrm{~min}$ at an excitation wavelength of $480 \mathrm{~nm}$ and emission of 610 $\mathrm{nm}$ using a Synergy HT Multi-Detection fluorescence microplate reader (Biotek Instruments, Colchester, VT). Duplicate samples were prepared, and NOX activity was expressed as the change in Et fluorescence per milligram protein per minute versus control (saline). Some samples were incubated in the presence of $1 \mu \mathrm{M}$ of the NOX inhibitor diphenyleneiodonium (DPI; Sigma) or $15 \mathrm{UI}$ of superoxide dismutase (SOD, Sigma) to corroborate the specificity of the assay.

\section{Immunoblot}

Tissue homogenates ( $50 \mu \mathrm{g}$ protein per lane) were subjected to SDS-PAGE. The resolved proteins were transferred to PVDF membranes at $120 \mathrm{~V}$ for $1 \mathrm{~h}$. The membranes were blocked overnight with $5 \%$ nonfat dry milk in TBS and treated, overnight at $4{ }^{\circ} \mathrm{C}$, with anti-NOX2/gp91phox (1:500; ab80508, Abcam, USA) and anti-GAPDH (1:3000; 14C10, Cell signaling, USA) antibodies. After further washing, the blots were incubated with alkaline phosphatase-conjugated secondary antibody (1:10000) for $1 \mathrm{~h}$ at room temperature. Bands were visualized by using the enhanced chemiluminescence system according to the manufacturer's recommendations (Bio-Rad Laboratories, Hercules, CA) and exposed to Kodak XAR-5 film.

\section{Caspase-3 activity}

Caspase- 3 activity was determined in striatal homogenates at different times (1, 3, 6, 12, and $24 \mathrm{~h})$ after glutamate administration (Fig. 1). Caspase-3 activity was assayed by a fluorogenic technique [51] in a luminescence spectrometer (Shimadzu, RF-5301PC), using the peptide Ac-VDVAD-AMC as a substrate to detect the proteolytic activity. Caspase activity was followed $30 \mathrm{~min}$ after addition of substrate $(80 \mu \mathrm{M})$ and tissue homogenate $(50 \mu \mathrm{g} / \mathrm{mL})$ in a standard solution. Results depicting caspase activity were calculated as the change in fluorescence intensity per milligram protein per minute and expressed as fold change versus control (saline).

\section{Cytokine levels}

Cytokine levels were measured using the mouse ultrasensitive ELISA kit assay for IL-1 $\beta$ (ab100704), IL-4 (ab100710), IL-6 (Abcam, ab100712), IL-10 (ab46103), IL-12 p40/70 (100699), TNF- $\alpha$ (100747), and TGF- $\beta$ (119557). The tissue samples, corresponding to $100 \mu \mathrm{g}$ of striatal protein (diluted 1:10), were obtained after different times $(1,3,6,12$, and $24 \mathrm{~h})$ of glutamate administration (Fig. 1) and were used for cytokines measurement according to the manufacturer's protocol (Abcam, MA, USA). Assays were carried out in a colorimetric spectrometer (Shimadzu, RF-5301PC). The results were calculated based on a concentration curve provided by the manufacturer and were expressed as picograms of cytokine per milligrams of protein. 


\section{Cylinder test of forelimb asymmetry}

Animals were examined for preferential use of the unilateral forelimb during upright postural support before and after glutamate administration (Fig. 1). Briefly, mice were placed in a pyro-glass cylinder $(10 \mathrm{~cm}$ in diameter) on a tabletop and video-recorded for $3 \mathrm{~min}$. The number of unilateral and bilateral wall contacts was recorded. The percentage of bilateral contacts was assessed on each test using the formula $100 \times$ bilateral contacts/total forelimb wall contacts, whereas the percentage of unilateral contacts was assessed using the formula $100 \times$ unilateral contacts/total forelimb wall contacts. The results are expressed as the percent of unilateral exploration [52].

\section{Adhesive removal test}

The animal cage was placed in the testing room at least 30 min before starting the experiment to allow habituation to the new environment. Animals were gently removed from the testing box and an adhesive tape strip (0.2-in. square) was placed on the snout (dorsal portion). Animals were returned to the testing cage and a timer was set. Conduct was observed and recorded for $60 \mathrm{~s}$ or until the piece of tape was removed with the forelimb. Training consisted of five trials (one per day), and testing after glutamate administration at different times $(1,3,6,12$, and 24h) was carried out (Fig. 1). Result indicated the latency to adhesive tape removal in seconds [53].

\section{Inverted grid test}

The inverted grid test was used to assess coordination and limbs muscular strength, especially related to distal musculature and digit manipulations. Mice were placed in the center of a horizontal square $\left(15 \mathrm{~cm}^{2}\right)$ grid consisting of a wire mesh $\left(0.5 \mathrm{~cm}^{2}\right)$ surrounded by wooden walls. The grid was placed $20 \mathrm{~cm}$ above a tabletop and was rotated upside down allowing mice to move freely. Each mouse was recorded for $60 \mathrm{~s}$. The time the mice remained and moved upside down was recorded. If a mouse fell from the mesh grid within $10 \mathrm{~s}$, additional trials were allowed ( $\max$ three trials) within an interval of $1 \mathrm{~min}$, in this case, latencies before falling were measured. The means \pm standard error of the mean (SEM) of three trials were calculated. No pretraining was performed, but a pretest of $30 \mathrm{~s}$ before the day of the experiment was carried out for habituation [53].

\section{Neurological dysfunction score}

All behavioral tests were conducted by the same experimenter in a quiet and low-lit room with white noise background. Pretests were conducted to exclude abnormally behaving animals. A combination score from a battery of three behavioral tests (adhesive test, inverted grip test, and cylinder test) was used to measure the neurological functional deficits (ND). We determined the grand NDs score (NDS) by combining all the tests, assuming an equal weight of each of the tests and assigning a value of 15 points to the maximum performance [53, 54].

\section{Statistical analysis}

Data were analyzed as means \pm SEM. The data were evaluated statistically by the two-way analysis of variance (ANOVA) for biochemical and histological tests and repeated measures ANOVA for behavioral tests, followed by Tukey's test for pairwise comparisons by using GraphPad Prism v6.0 and SigmaPlot 12.3 software. In the case of significance, a further ad hoc two-tailed Student's $t$ test was applied. Significance was considered when $p<0.05$.

\section{Results}

Striatal excitotoxic lesion and neuronal degeneration are minor in NOX-2 KO mice

To determine the impact of excitotoxic damage, both lesion volume and neuronal degeneration were evaluated in WT and NOX-2 KO mice as detailed in the "Methods" section. Representative tissue sections from WT and NOX-2 KO animals stained with cresyl violet are shown in Fig. 2a. WT and NOX2 KO mice treatment with saline, as a control of the procedure, developed a small lesion similar in both groups $(0.05 \pm$ $0.02 \mathrm{~mm}^{3}$ and $0.03 \pm 0.01 \mathrm{~mm}^{3}$, respectively). As it was expected, in the groups treated with glutamate, NOX-2 KO mice showed only $38 \%$ of the lesion observed in WT mice (WT, $1.2 \pm 0.14 \mathrm{~mm}^{3}$ vs NOX-2 KO, $0.45 \pm 0.10 \mathrm{~mm}^{3} p<0.05$; Fig. $2 \mathrm{~b}$ ).

The FJB-positive cells were counted in tissue sections $24 \mathrm{~h}$ after glutamate injection (Fig. 2c). Again, a higher number of degenerated cells were found in WT mice injected with glutamate $(82.3 \pm 11.1$ cells/ $\left.\mathrm{mm}^{2}\right)$ than in saline-injected animals $(3.06 \pm 0.6$ cells/ $\left.\mathrm{mm}^{2} ; p<0.05\right)$. In accordance to the tissue lesion measurements, the number of FJB-positive cells in NOX-2 KO mice $\left(35.9 \pm 7.5\right.$ cells $\left./ \mathrm{mm}^{2} ; p<0.05\right)$ were about half of that observed in WT mice treated with glutamate. Representative tissue sections from WT and NOX-2 KO animals showing FJB-labeled cells are shown in Fig. 2a. Together, these results confirm that NOX-2 participates in the tissue injury and neuronal degeneration induced by glutamate.

\section{NOX-2 activity increases during excitotoxic damage}

In the present study, we measured NOX activity in striatal homogenates of WT and NOX-2 KO mice at different times after glutamate injection $(0.5,1,3,6,12$, and $24 \mathrm{~h})$. An increase in the enzyme activity over saline (control) levels was detected at $1 \mathrm{~h}$ after glutamate administration in WT mice ( $225 \pm 27 \%$ vs control, $p<0.05$; 


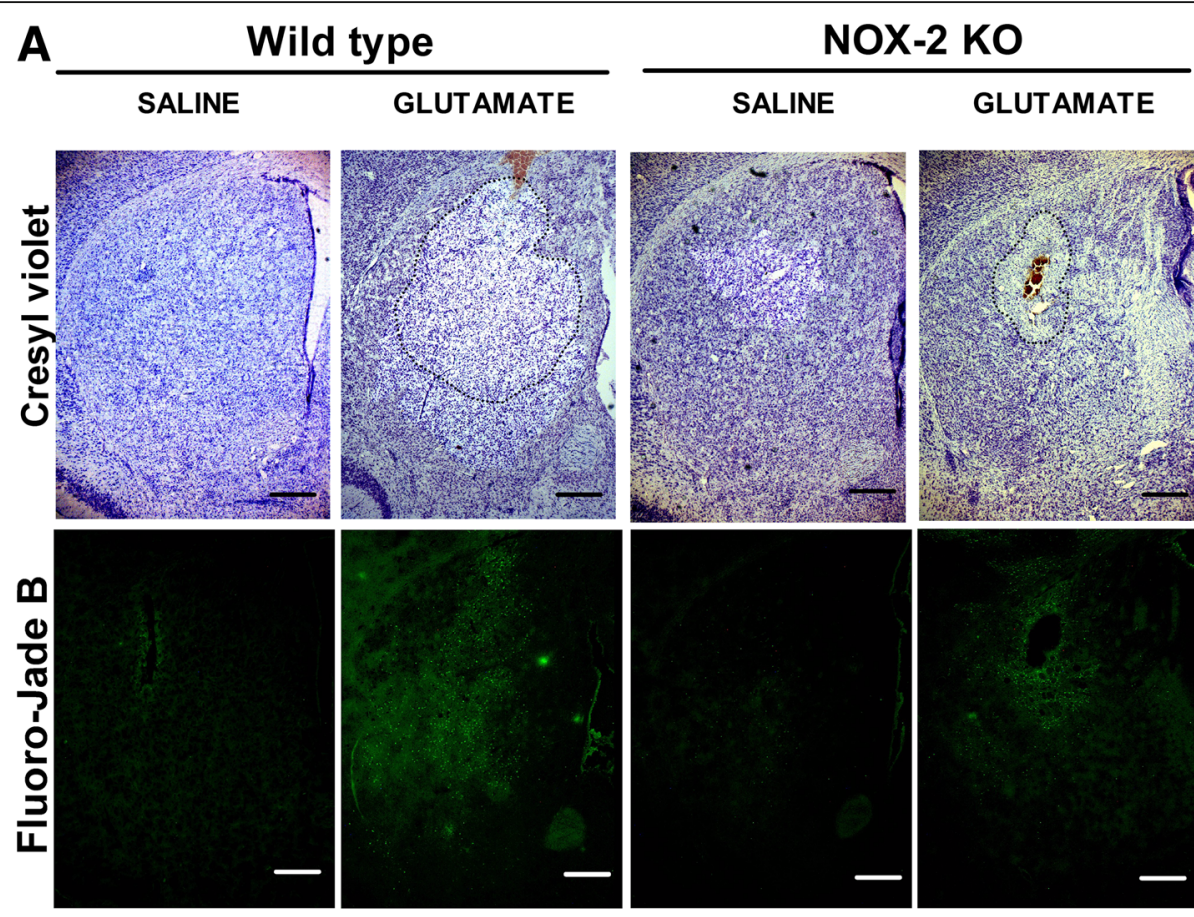

B

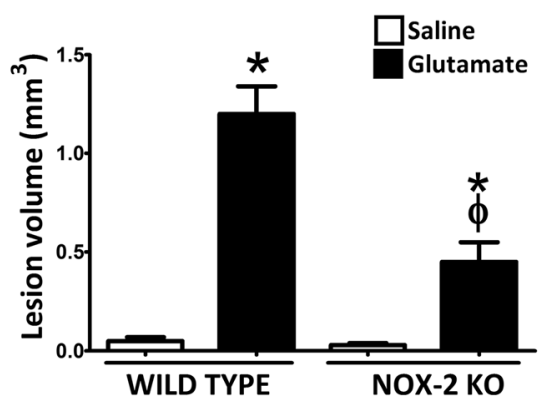

C

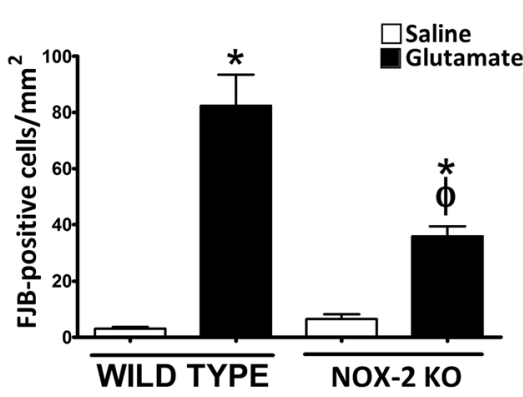

Fig. 2 Lesion area and neuronal degeneration in wild-type and NOX-2 KO mice injected with glutamate in the striatum. Histological sections were obtained after $24 \mathrm{~h}$ of intracerebral administration of saline $(\mathrm{NaCl}$ 0.9\%) or glutamate (1 M) as detailed in the "Methods" section. a Representative micrographs of coronal striatal sections showing striatal lesions stained with cresyl violet and damaged cells positive to Fluoro-Jade B. The dotted line delimits the area of lesion of mice treated with glutamate. The scale bars represent $200 \mu \mathrm{m}$. $\mathbf{b}$ Quantification of the lesion volume $24 \mathrm{~h}$ after saline or glutamate injection is expressed in cubic millimeters. c Total number of FJB-positive cells counted in three slices per mice. Data are expressed as means \pm SEM of five independent experiments. ${ }^{*} p<0.05$ vs the corresponding saline control; ${ }^{\varphi} p<0.05$ vs wild-type mouse (WT) treated with glutamate

Fig. 3). Although the NOX activity remained increased during $24 \mathrm{~h}$, we observed two peaks of activation, the first $1 \mathrm{~h}$ after glutamate injection ( $130 \pm 15 \%$ vs control) and the second after $12 \mathrm{~h}(195 \pm 10 \%$ vs control). The increase of NOX activity in NOX-2 KO mice after glutamate administration was more discrete and about half of that in WT mice at 12 and $24 \mathrm{~h}(p<0.05)$. These results indicate that the administration of glutamate leads to an early and a late activation of NOX during the excitotoxic damage and that this activation is attenuated in NOX-2 $\mathrm{KO}$ animals.
We found that NOX2 protein was upregulated by glutamate treatment in a time-dependent manner. The protein levels increased from $6 \mathrm{~h}$ and continued increasing after 12 and $24 \mathrm{~h}$ (Additional file 1: Figure S1). The observed changes in protein levels did not correlate with the observed changes in NOX activity. For example, at 1 $\mathrm{h}$ no change in the protein was observed, while a large increase in NOX activity occurred (Fig. 3 and Additional file 1: Figure S1). This suggests that the observed changes in NOX activity are regulated by other conditions than protein enrichment. 


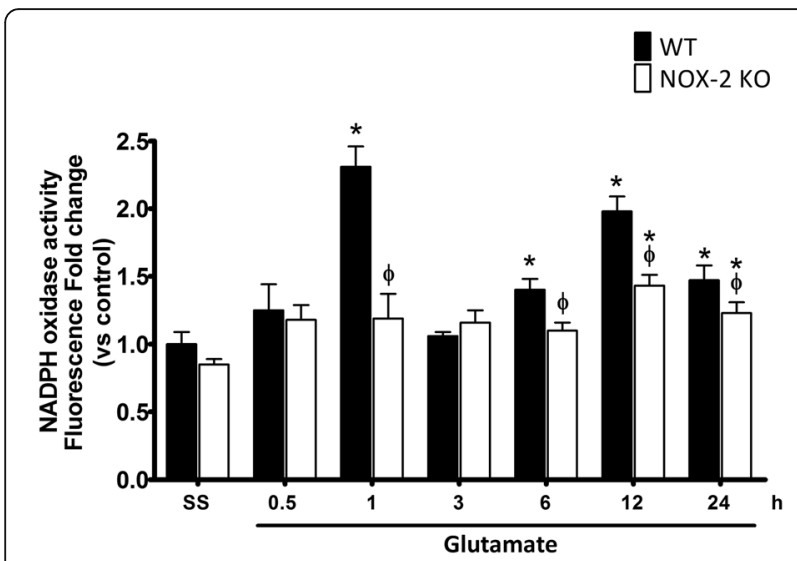

Fig. 3 NOX-2 activity during excitotoxic damage in wild-type and NOX-2 KO mice. NOX activity was evaluated as the change of fluorescence intensity resulting from dihydroethidium (DHE) oxidation to ethidium (Et) in striatum homogenates of WT and NOX$2 \mathrm{KO}$ mice treated with glutamate ( $1 \mathrm{M}) 0.5,1,3,6,12$, and $24 \mathrm{~h}$ after glutamate administration. Data are expressed as fold change of Et fluorescence relative to WT saline. Values are means \pm SEM of four independent experiments. ${ }^{*} p<0.05$ vs the corresponding saline control; ${ }^{\varphi} p<0.05$ vs the corresponding wild-type mouse (WT) treated with glutamate

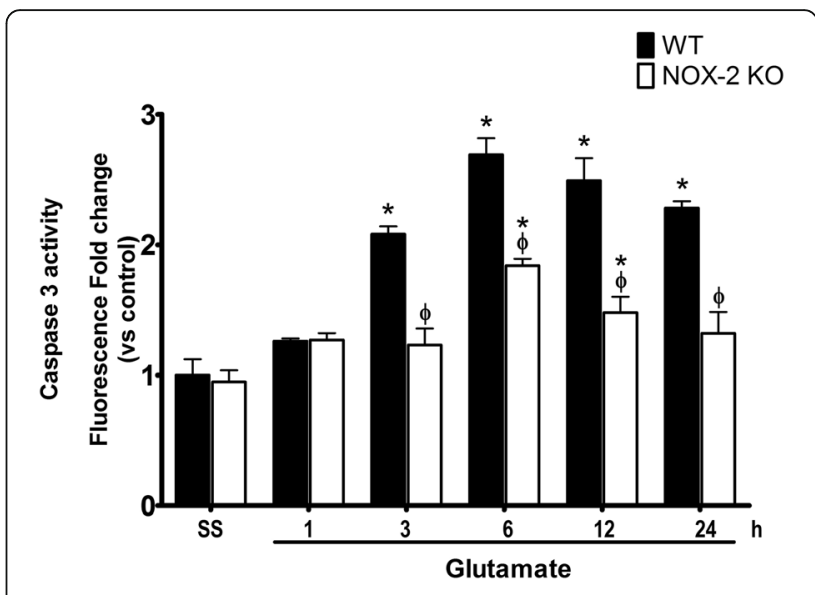

Fig. 4 Caspase-3 activity in wild-type mice and NOX-2 KO after administration of glutamate. Active caspase- 3 was measured in striatum homogenates after 1, 3, 6, 12, and $24 \mathrm{~h}$ of glutamate (1 M) administration in WT and NOX-2 KO mice. Fluorescence produced by the cleavage of the specific substrate for caspase- 3 was quantified in relative units of fluorescence (FRU) and the results are expressed as the fluorescence fold change relative to WT saline. Values are mean \pm SEM of three independent experiments. ${ }^{*} p<0.05$ vs the corresponding saline control; $\varphi_{p}<0.05$ vs corresponding wild-type mouse (WT) treated with glutamate
NOX-2 KO mice resistance to excitotoxic damage involves a decrease in caspase- 3 activation

Intrastriatal injection of glutamate causes an increase of caspase- 3 activation at $3 \mathrm{~h}$ after glutamate administration in WT $(208 \pm 9 \%$ vs control) and after $6 \mathrm{~h}$ in NOX-2 KO mice $(197 \pm 16 \%$ vs control). We found that after $6 \mathrm{~h}$, caspase- 3 activation was lower in NOX-2 KO $(p<0.05)$ as compared to WT mice (NOX-2 KO $180 \pm 10 \%$ vs WT $280 \pm 25 \%, p<0.05$ ), and the same effect is observed during the following $24 \mathrm{~h}$ (NOX-2 KO $57 \pm 15 \%$ vs WT $128 \pm 9 \%, p<0.05$; Fig. 4). Thus, NOX-2 KO mice exhibit a lower activation of caspase-3 during excitotoxic injury induced by the administration of glutamate.

\section{NOX-2 KO mice exhibit better motor recovery than wild-} type mice after excitotoxic damage

Striatum lesions lead to alterations in the control of voluntary movements and muscle tone, predominantly in the forelimbs [53]. We therefore explored the degree of functional compromise resulting from the excitotoxic damage as an index of striatal injury. To assign a neurological deficit score (NDS), we evaluated three tests in WT and NOX-2 KO mice to obtain a motor score (Fig. 5).

The cylinder test indicates the latency of forelimb asymmetry (Fig. 5a). Prior to glutamate administration, WT and NOX-2 KO mice tended to preferentially make bilateral wall contacts in the cylinder before glutamate administration (WT $10 \pm 3 \%$ and NOX-2 KO $8 \pm 2 \%$ of unilateral contacts). Excitotoxic damage in WT mice resulted in an early and sustained decrease in bilateral contacts from $1 \mathrm{~h}(90 \pm 5 \%$ unilateral contacts $)$ to $24 \mathrm{~h}$ (50 $\pm 4 \%$ unilateral contacts). NOX-2 KO mice show a similar compromised motor function that WT mice at 1 h $(78 \pm 6 \%$ unilateral contacts; $p<0.05)$, but despite the fact that they exhibited a severe decline at short time, they managed to recover at $24 \mathrm{~h}(18 \pm 8 \%$ unilateral contacts), unlike the WT, which do not reach control levels $(p>0.05$; Fig. 5a).

The adhesive removal test evaluates the control of voluntary movements (Fig. 5b). Prior to administration of glutamate, both WT and NOX-2 KO mice took a maximum of $14 \mathrm{~s}$ to remove the adhesive (WT $12 \pm 2 \mathrm{~s}$ and NOX-2 KO $10 \pm 2 \mathrm{~s}$ ). After $1 \mathrm{~h}$ of glutamate administration, WT mice were unable to remove the label before $60 \mathrm{~s}$. After $24 \mathrm{~h}$, WT mice showed an improvement in the ability to remove the label; however, the time to removal was markedly higher than that shown by the saline controls (WT + GLU $37 \pm 5 \mathrm{~s}$ vs WT + SS $11 \pm 3 \mathrm{~s}, p$ $<0.05)$. NOX-2 KO mice had a similar performance to that shown by the WT mice after $1 \mathrm{~h}$ (WT $55 \pm 5 \mathrm{~s}$ vs NOX-2 KO $50 \pm 7 \mathrm{~s}, p>0.05)$. However, at $6 \mathrm{~h}$, the NOX-2 KO mice showed a marked recovery as compared to WT mice (WT $44 \pm 5 \mathrm{~s}$ vs NOX-2 KO $22 \pm 4 \mathrm{~s}$; $p<0.05)$. It reaches control levels after $12 \mathrm{~h}$, a situation that did not occur in WT mice (WT $37 \pm 5 \mathrm{~s}$ vs NOX-2 KO $12 \pm 3$ s, $p<0.05$; Fig. 5b).

Finally, the inverted grid test indirectly allows evaluation of the muscle tone of the mice extremities (Fig. 5c). 

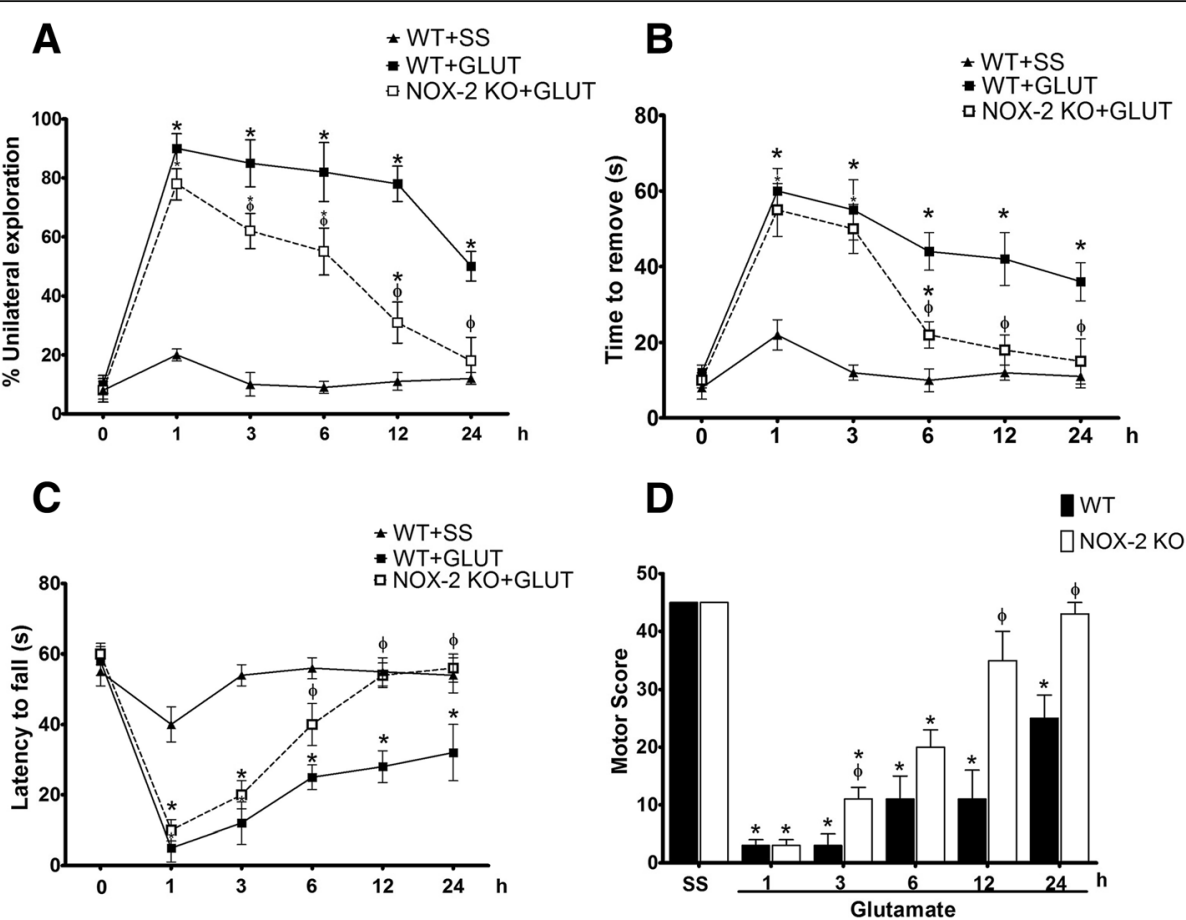

Fig. 5 Motor activity recovery after glutamate administration in NOX-2 KO mice. Performance of wild-type (WT + SS) animals and WT or NOX-2 KO mice injected with glutamate (WT + GLUT; NOX-2 KO + GLUT) was evaluated in three tests of motor behavior at 1, 3, 6, 12, and 24 h after glutamate intracerebral injection. These tests were later integrated to obtain a motor score that reflects functional deterioration. a Cylinder test in which each mouse obtained a percentage based on the ratio of unilateral and bilateral explorations performed in three trials, of 3 min each; the percentage was expressed as mean \pm SEM of eight independent tests. $\mathbf{b}$ Adhesive removal test that quantifies the time in which the animals remove a label previously placed by the examiner. The time of removal was quantified in seconds and was expressed as means \pm SEM of six independent animals. $\mathbf{c}$ The tone and muscle strength of the four limbs was evaluated by exposing the mice to the inverted grid test in which the decay time was quantified for three non-consecutive opportunities of a maximum of $60 \mathrm{~s}$ of duration. The results are expressed as means \pm SEM of the latency to fall of six independent tests. $\mathbf{d}$ To integrate the three previous tests, an arbitrary score was assigned to the performance of each animal, giving the highest score to the performance of the mice injected with saline (45 points). The results are expressed in arbitrary units of motor score as the mean \pm SEM of the latency to fall of six independent tests. ${ }^{*} p<0.05$ vs the corresponding saline control; ${ }^{\varphi} p<0.05$ vs the corresponding wild-type (WT) mouse treated with glutamate

Control mice remained attached to the inverted grid for about a minute $(56 \pm 4 \mathrm{~s})$, which is considered an adequate performance and is established as the baseline. After 1 hour of glutamate administration, both the WT and NOX-2 $\mathrm{KO}$ mice were unable to remain attached for long time to the grid (WT $5 \pm 4 \mathrm{~s}$ and NOX-2 KO 10 $\pm 3 \mathrm{~s})$. In comparison to WT mice, the NOX-2 KO mice showed a better functional recovery from $6 \mathrm{~h}$ after the event (WT $25 \pm 4$ vs NOX-2 KO $40 \pm 6 \mathrm{~s} p<0.05$ ) reaching a performance similar to control animals from $12 \mathrm{~h}$, which is not observed in WT mice (WT $32 \pm 8$ vs NOX-2 KO $54 \pm 4$ s $p>0.05$; Fig. 5c).

Motor function parameters were integrated into a NDS (Fig. 5d). To that, each test was given an equivalent weight in the score, assigning an arbitrary value of 15 points (for each test) to the control animals treated with saline solution. Therefore, a poor performance during the test corresponded to a decrease in the points awarded [55]. The WT mice treated with glutamate showed a poor score in the first $3 \mathrm{~h}$ ( $3 \pm 1$ points), which improved at $12 \mathrm{~h}(11 \pm 5$ points $)$ and $24 \mathrm{~h}(25 \pm 4$ points). NOX-2 KO mice treated with glutamate obtained a poor score in the first hour ( $3 \pm 1$ points), reaching a marked improvement at $24 \mathrm{~h}$ with a performance similar to the control animals ( $43 \pm 2$ points, $p>0.05$; Fig. $5 d$ ). As we observed in the previous tests, the functional recovery of the NOX-2 KO mice surpasses that observed in WT mice after $12 \mathrm{~h}$ of glutamate administration (WT $11 \pm 5$ vs NOX-2 KO $35 \pm 4$ s $p<0.05)$. Based on these findings, we suggest that NOX-2 activity is associated with a worst functional motor recovery after glutamate administration.

\section{The pattern of cytokine production in response to excitotoxic damage depends on NOX-2}

The resolution of the excitotoxic damage depends on the inflammatory response, which aims to remove damaged tissue and recover functions [56]. We characterized the inflammatory response to excitotoxic damage and evaluated the involvement of NOX-2 in the production 
of cytokines associated with the inflammatory response in the CNS (Fig. 6a).

Regarding the inflammatory cytokines, we observed an increase of IL- $1 \beta$ in the WT $\left(701 \pm 30 \mathrm{pg} / \mathrm{mg}^{-1}\right.$ protein) after $6 \mathrm{~h}$ of glutamate administration, when compared with the saline control $\left(298 \pm 41 \mathrm{pg} / \mathrm{mg}^{-1}\right.$ protein). In a similar manner, the NOX-2 $\mathrm{KO}$ mice depicted and increased value for this interleukin (682 $\pm 24 \mathrm{pg} / \mathrm{mg}^{-1}$ protein). At $12 \mathrm{~h}$, the IL-1 $\beta$ levels were markedly reduced in both conditions, but still above the control (WT + GLU $400.7 \pm 22$ vs. NOX-2 KO + GLU $420 \pm 15 \mathrm{pg} / \mathrm{mg}^{-1}$ protein, $\left.p<0.05\right)$, returning to control levels at $24 \mathrm{~h}$ (WT + GLU, $380 \pm 58$ and NOX-2 KO + GLU, $401 \pm 63 \mathrm{pg} / \mathrm{mg}$ protein; Fig. 6a). No differences were found between WT mice and NOX-2 KO in the production of IL-1 $\beta$.
Excitotoxic damage also caused a similar increase of the inflammatory cytokine IL-6 in both groups at $6 \mathrm{~h}$ and $12 \mathrm{~h}(\mathrm{WT}+\mathrm{GLU}, 650 \pm 85$ and NOX-2 KO + GLU, $553 \pm 91 \mathrm{pg} / \mathrm{mg}^{-1}$ protein). Unexpectedly, after $24 \mathrm{~h}$ of glutamate administration, NOX-2 $\mathrm{KO}$ maintained high levels of IL-6 compared to WT mice (WT $381 \pm 41$ vs NOX-2 KO $581 \pm 43 \mathrm{pg} / \mathrm{mg}^{-1}$ protein, $p<0.05$; Fig. $6 \mathrm{c}$ ).

IL-12 levels increased at the first hour after glutamate treatment in both WT $\left(423 \pm 52 \mathrm{pg} / \mathrm{mg}^{-1}\right.$ protein $)$ and NOX-2 KO $\left(475 \pm 74 \mathrm{pg} / \mathrm{mg}^{-1}\right.$ protein $)$ mice as compared to the saline control (WT $282 \pm 28$ ) and saline NOX-2 KO $\left(321 \pm 31 \mathrm{pg} / \mathrm{mg}^{-1}\right.$ protein, $\left.p<0.05\right)$, respectively. After $6 \mathrm{~h}$, WT mice treated with glutamate showed a maximum increase, which was significantly higher than that observed in NOX-2 KO mice (WT 673 \pm 39 vs NOX-2 KO $385 \pm 35 \mathrm{pg} / \mathrm{mg}^{-1}$ protein, $p<0.05$ ).

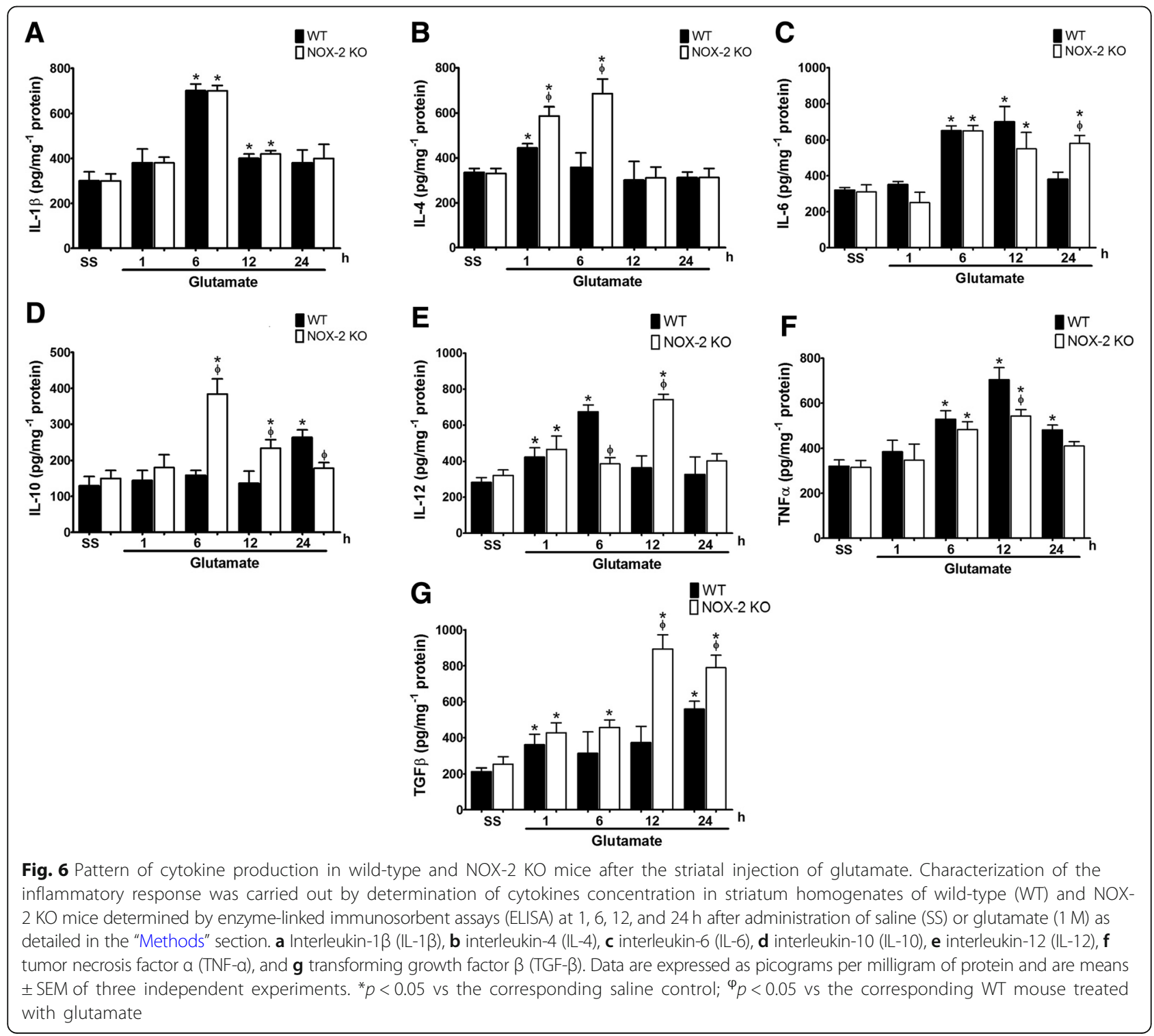


At $12 \mathrm{~h}$, this pattern was inverse since IL-12 levels were much higher in NOX-2 KO than in WT mice (WT 363 \pm 67 vs NOX-2 KO $743 \pm 29 \mathrm{pg} / \mathrm{mg}^{-1}$ protein, $p<0.05$; Fig. 6e).

We observed an increase of TNF- $\alpha$ induced by glutamate in both WT $\left(528 \pm 39 \mathrm{pg} / \mathrm{mg}^{-1}\right.$ protein) and NOX-2 KO mice at $6 \mathrm{~h}\left(483 \pm 35 \mathrm{pg} / \mathrm{mg}^{-1}\right.$ protein $)$ and $12 \mathrm{~h}$ (WT 704 \pm 54 ; NOX-2 KO $542 \pm 29 \mathrm{pg} / \mathrm{mg}^{-1}$ protein). The production of TNF- $\alpha$ in NOX-2 KO mice was always lower than in WT, particularly at 6 and $12 \mathrm{~h}$. After $24 \mathrm{~h}$, the observed increase was reduced in both WT $(482 \pm 22 \mathrm{pg} / \mathrm{mg}$ protein) and NOX-2 KO mice $\left(410 \pm 20 \mathrm{pg} / \mathrm{mg}^{-1}\right.$ protein, $p>0.05$; Fig. $\left.6 \mathrm{f}\right)$.

Regarding the production of anti-inflammatory cytokines, we measured the concentration of some of the anti-inflammatory cytokines previously reported in the CNS, such as IL-4, IL-10, and TGF- $\beta[21,22]$. One hour after glutamate administration, NOX-2 KO mice showed an almost twofold increase in the production of IL-4 as compared to control (saline) (NOX-2 KO $586 \pm 42$ vs $\mathrm{NOX}-2 \mathrm{KO}+\mathrm{SS} 330 \pm 32 \mathrm{pg} / \mathrm{mg}^{-1}$ protein; $\left.p<0.05\right)$, while in WT mice, glutamate induced an increase of $125 \%$ with respect to the saline control (WT + GLU 443 \pm 20 vs WT + SS $335 \pm 18 \mathrm{pg} / \mathrm{mg}^{-1}$ protein; $p<0.05$ ). The observed difference between WT and NOX-2 KO was markedly increased at $6 \mathrm{~h}$ (WT $357 \pm 54$ vs NOX-2 KO $685 \pm 65 \mathrm{pg} / \mathrm{mg}$ protein, $p<0.05$; Fig. $6 \mathrm{~b}$ ). At 12 and 24 , no difference was observed between groups and values returned to control values.

The administration of glutamate to NOX-2 KO mice caused an increase of IL-10 more than double respect to WT mice at $6 \mathrm{~h}$ (WT $158 \pm 14$ vs NOX-2 KO $384 \pm 42$ $\mathrm{pg} / \mathrm{mg}^{-1}$ protein, $\left.p<0.05\right)$ and this increase was maintained only in NOX-2 KO group until $12 \mathrm{~h}$ (WT $136 \pm$ 34 vs NOX-2 KO $234 \pm 24 \mathrm{pg} / \mathrm{mg}^{-1}$ protein, $p<0.05$ ). However, at $24 \mathrm{~h}$, we observe an increase of IL-10 in WT, while values in NOX-2 KO continued decreasing (WT $263 \pm 21$ vs NOX-2 KO $178 \pm 18 \mathrm{pg} / \mathrm{mg}^{-1}$ protein, $p<0.05$; Fig. 6d).

Regarding the production of TGF- $\beta$ (Fig. 6g), a negative regulatory cytokine, we observed a similar increase both in WT as NOX-2 KO mice treated with glutamate at $1 \mathrm{~h}$ (WT $360 \pm 59$ vs NOX-2 KO $427 \pm 56 \mathrm{pg} / \mathrm{mg}^{-1}$ protein, $p$ $<0.05)$. This increase was maintained only in the NOX-2 $\mathrm{KO}$ group, until $24 \mathrm{~h}$, reaching a maximum concentration at $12 \mathrm{~h}$ (WT $372 \pm 91$ vs NOX-2 KO $893 \pm 79 \mathrm{pg} / \mathrm{mg}^{-1}$ protein, $p<0.05)$. At this time, it reaches more than double than that found in WT mice. In contrast, WT mice showed only a second increase at $24 \mathrm{~h}$, which was lower than that observed in NOX-2 KO (WT $557 \pm 45$ vs NOX-2 KO $789 \pm 69 \mathrm{pg} / \mathrm{mg}^{-1}$ protein, $\left.p<0.05\right)$. These results suggest that the change in the cytokines profile in NOX-2 KO mice is characterized by an increase in the production of anti-inflammatory cytokines and that this increase occurs preferentially at early times during the excitotoxic event.

\section{Administration of IL-4 partially prevents the excitotoxic lesion}

One of the most evident differences in the response of the NOX-2 KO mice to the excitotoxic damage was the increase in the production of anti-inflammatory cytokines; therefore, we treated animals with exogenous IL-4 or IL-10 simultaneously to glutamate administration and evaluated neuronal degeneration and lesion volume. Representative tissue sections from WT and NOX-2 KO animals stained with cresyl violet and Fluoro-Jade B are shown in Fig. 7a. In the case of WT mice treated with IL-4, we observed a significant decrease in the lesion volume (WT $1.2 \pm 0.14$ vs WT + IL-4 $0.72 \pm 0.05 p<$ 0.05 ; Fig. 7b), as well as a decrease in degenerating cells (WT $82.3 \pm 11.1$ vs WT + IL- $435.4 \pm 4.7$ cells $/ \mathrm{mm}^{2} p<$ $0.05)$ as compared to mice administered only with glutamate (Fig. 7c).

NOX activity and caspase- 3 activation are regulated by IL4 in the excitotoxic process

Since the NOX-2 KO mice showed an increased production of IL-4, we explored the possibility of reciprocal regulation through the determination of NOX activity in WT mice treated with IL-4 (Fig. 8). Under these conditions, WT mice treated with IL- 4 showed a $50 \%$ reduction in NOX activity induced by glutamate only at $12 \mathrm{~h}$ (GLU $85 \pm 12 \%$ and GLU + IL- 4 vs $44 \pm 12 \%$ above control $p<0.05$; Fig. 8). Concordantly, mice treated with IL-4 also showed a significant reduction in the activation of caspase-3 after $12 \mathrm{~h}$ (GLU $249 \pm 10 \%$ vs GLU + IL-4 $187 \pm 9 \%$ compared with controls, $p<0.05)$ that was maintained at $24 \mathrm{~h}$ (GLU $229 \pm 9 \%$ vs GLU + IL-4 $172 \pm$ $10 \%$ compared with the control $p<0.05$; Fig. 9).

\section{The administration of IL-10 reduces the lesion induced by excitotoxic damage}

After glutamate administration, we found that the lesion volume was also markedly reduced in mice treated with IL-10. Representative tissue sections from WT and NOX-2 KO animals stained with cresyl violet and Fluoro-Jade B are shown in Fig. 10a. Animals treated with IL-10 showed a decrease of more than $60 \%$ in the lesion volume as compared to the untreated mice (GLU $1.2 \pm 1.14$ vs $\mathrm{GLU}+\mathrm{L}-10 \quad 0.45 \pm 0.05 \mathrm{~mm}^{3} \quad p<0.05$; Fig. 10b). As for the degenerating cells, the administration of IL-10 also decreased the number of positive cells to Fluoro-Jade B by $60 \%$ (GLU $83.4 \pm 11.3$ vs GLU + IL-10 $32.3 \pm 4.6 \mathrm{~mm}^{3} p<0.05$; Fig. 10c). 

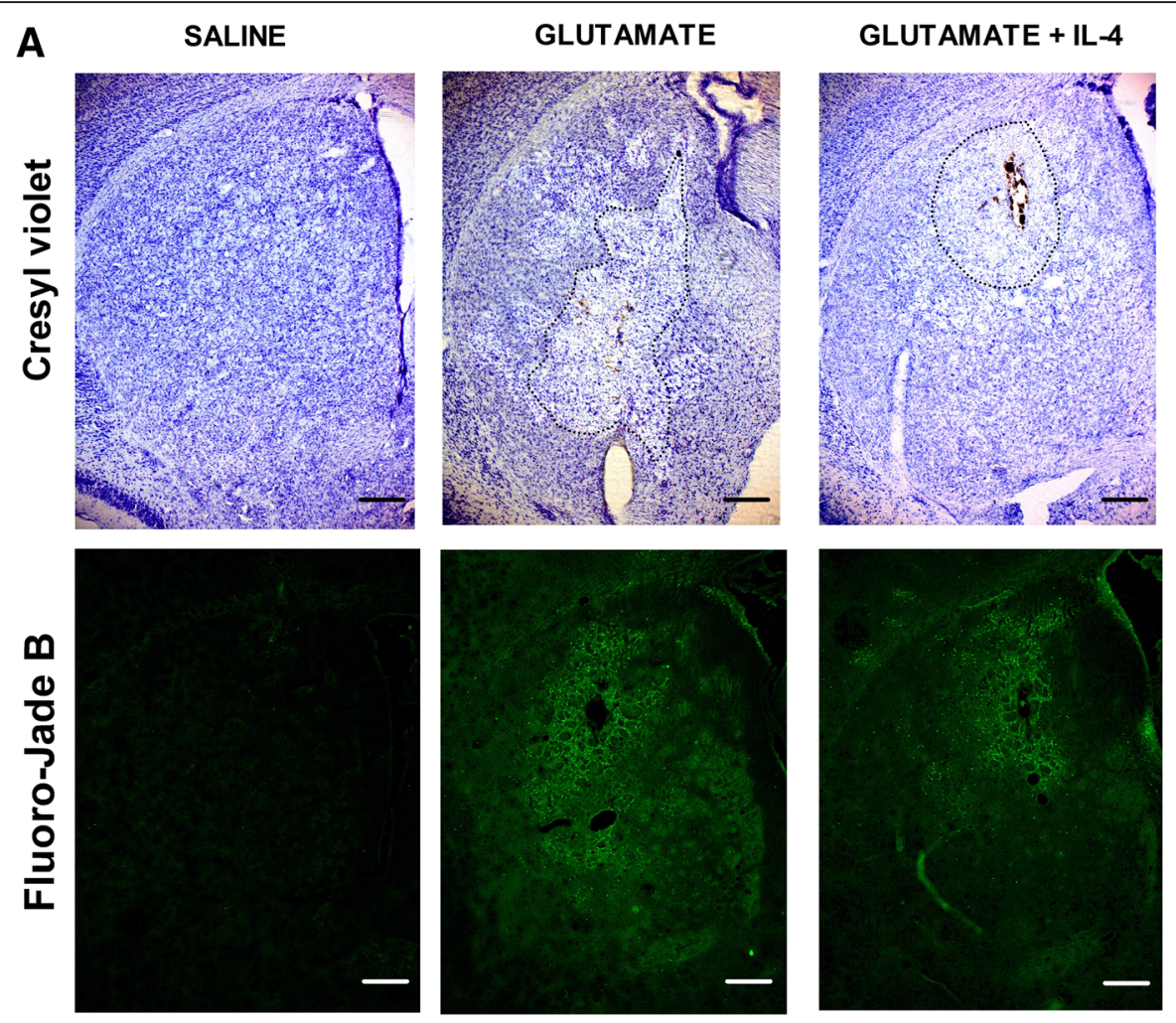

B

C
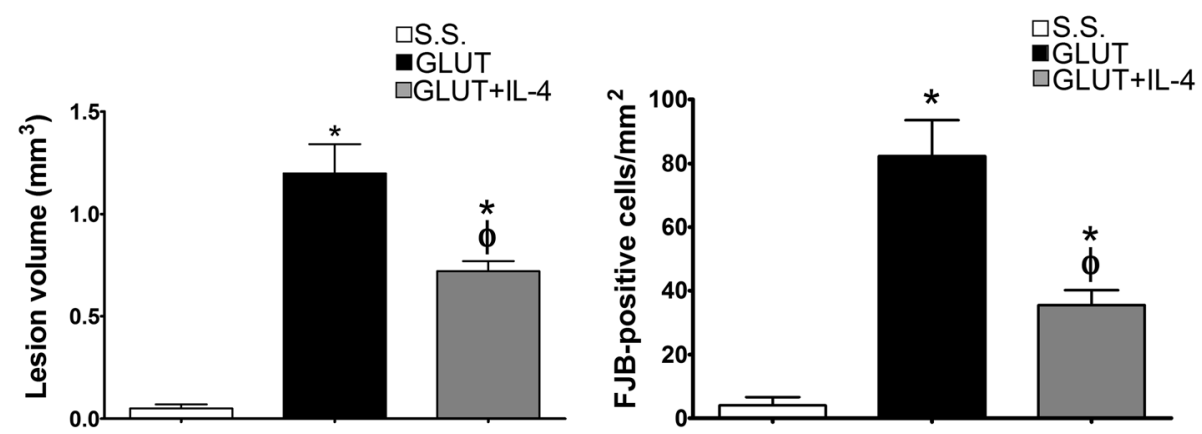

Fig. 7 Effect IL-4 on the striatal lesion and neuronal degeneration in wild-type mice treated with glutamate. Histological sections of wild-type (WT) mice were obtained after $24 \mathrm{~h}$ of intracerebral administration of $\mathrm{NaCl} 0.9 \%$ (S.S.), only glutamate (GLUT) or glutamate $+0.7 \mathrm{ng} / \mathrm{mL}$ of IL-4 (GLUT + IL4) as detailed in the "Methods" section. a Representative micrographs of coronal striatal sections showing lesions stained with cresyl violet and damaged cells positive to Fluoro-Jade B. The dotted line delimits the area of lesion of mice treated with glutamate. The scale bars represent $200 \mu \mathrm{m}$. b Quantification of the lesion volume $24 \mathrm{~h}$ after saline or glutamate injection is expressed in cubic millimeters. c Total number of FJB-positive cells were counted in three slices per mice. Data are expressed as mean \pm SEM of six independent experiments. ${ }^{*} p<0.05$ vs saline control (S.S.); ${ }^{\varphi} p<0.05$ vs the corresponding mouse treated only with glutamate (GLUT)

The NOX activity and caspase- 3 activation are regulated negatively by IL-10

When WT animals were simultaneously treated with glutamate and IL-10, NOX activity was markedly reduced at $1 \mathrm{~h}$ (GLU $231 \pm 25 \%$ vs GLU + IL-10 $108 \pm 7 \%$ of the control, $p<0.05$ ); $6 \mathrm{~h}$ (GLU $141 \pm 5 \%$ vs GLU + IL-10 $115 \pm 4 \%$ compared with controls, $p<0.05)$; and $12 \mathrm{~h}$ (GLU $195 \pm 12 \%$ vs GLU + IL-10 $132 \pm 7 \%$ of the control, $p<0.05)$, as compared to mice injected only with glutamate. Nevertheless, $24 \mathrm{~h}$ after the excitotoxic insult, both groups showed similar levels of catalytic activity (GLU $147 \pm 4 \%$ vs GLU + IL-10 134 $\pm 5 \% p>0.05$; Fig. 11).

Under these conditions, IL-10 also decreased the activity of caspase-3. As we showed previously, the administration of glutamate promotes the increase of active caspase- 3 from 3 to up $24 \mathrm{~h}$ after the injection. The co-administration of IL-10 reduced caspase- 3 activation 


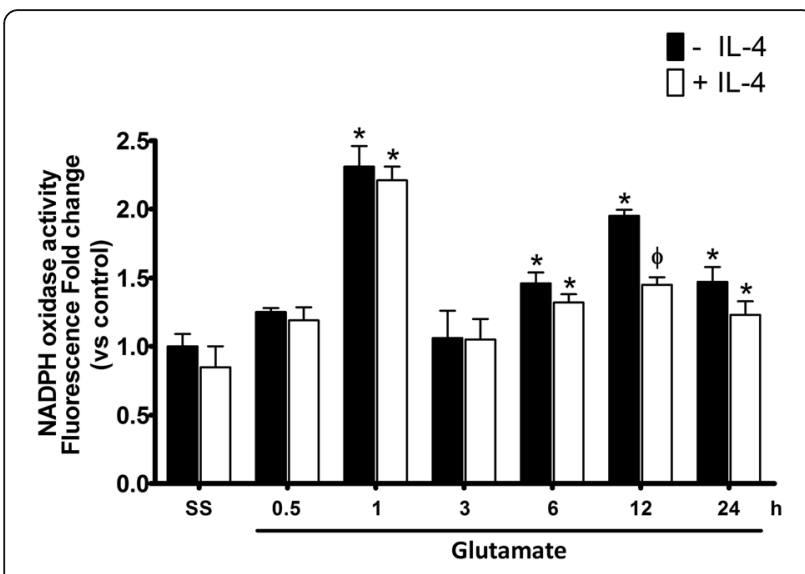

Fig. 8 NOX activity in wild type mice treated with IL-4 after glutamate administration. NOX activity was evaluated in WT mice treated with $\mathrm{NaCl} 0.9 \%$ (S.S.), only glutamate (- IL-4) or glutamate $+0.7 \mathrm{ng} / \mathrm{mL}$ of interleukin-4 (+IL4); the determination of NOX activity was measured by the fluorescence resulting from the dihydroethidium (DHE) oxidation in striatal homogenates of mice from 0.5 to $24 \mathrm{~h}(0.5,1,3,6$, 12 , and $24 \mathrm{~h}$ ) after glutamate administration. Data are expressed as fold change of fluorescence relative to saline without IL-4. Values are means \pm SEM of three independent experiments. ${ }^{*} p<0.05$ vs the corresponding saline control; ${ }^{\varphi_{p}}<0.05$ vs the corresponding time of mice treated with glutamate alone

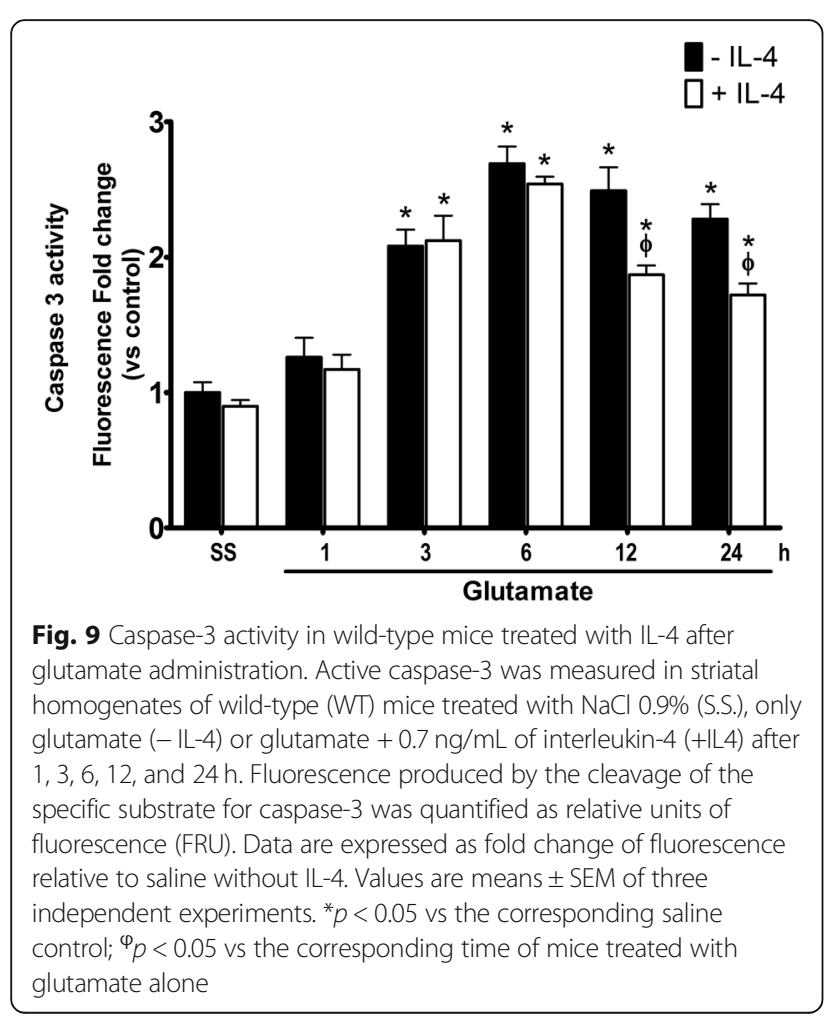

by $90 \%$ at 3 h (GLU $201 \pm 18 \%$ vs GLU + IL-10 $112 \pm 4 \%$ above control, $p<0.05$ ) and $24 \mathrm{~h}$ (GLU $228 \pm 27 \%$ vs GLU + IL-10 $118 \pm 6 \%$ above control, $p<0.05)$ after the injection. At $6 \mathrm{~h}$ and $12 \mathrm{~h}$, it decreased approximately $50 \%$ (GLU $270 \pm 30 \%$ vs GLU + IL-10 $194 \pm 15 \%$ of the controls, $p<0.05$; GLU $249 \pm 10 \%$ vs GLU + IL-10 $177 \pm$ $6 \%$ compared with controls, $p<0.05$; Fig. 12).

\section{IL-10 administration improves motor recovery in mice after excitotoxic damage}

Mice treated with IL-10 had a better performance in tests of motor behavior after glutamate administration (Fig. 13). In the cylinder test, although mice treated with IL-10 showed a performance similar to those that did not receive treatment, at $1 \mathrm{~h}$ (GLU $10 \pm 3 \%$ vs GLU + IL-10 $8 \pm 2$ unilateral contacts $p<0.05)$ they were able to recover the control level at $6 \mathrm{~h}$ (GLU $82 \pm 5 \%$ vs GLU + IL-10 $20 \pm 4 \%$ unilateral contacts, $p<0.05)$, while this did not happen in the untreated mice (Fig. 13a). In the adhesive test, mice treated with IL-10 were also able to recover baseline performance at $3 \mathrm{~h}$ (GLU $55 \pm 8 \mathrm{~s}$ and GLU + IL-10 $20 \pm 6.5 \mathrm{~s}, p<0.05)$, while those not treated did not reach these recovery levels in $24 \mathrm{~h}$ (GLU $36 \pm 5 \mathrm{~s}$ vs GLU + IL-10 $15 \pm 5 \mathrm{~s}, \quad p<0.05$; Fig. 13b). In the inverted grid test, mice treated with IL-10 had a better performance than the untreated mice from the first hour after glutamate treatment (GLU $5 \pm 4 \mathrm{~s}$ vs GLU + IL-10 $26 \pm 3 \mathrm{~s} p<0.05)$. In contrast to the animals treated with glutamate alone, these animals recovered to values similar to the control group after $12 \mathrm{~h}$ (SS $58 \pm 2 \mathrm{~s}$ vs GLU + IL-10 $50 \pm 4 \mathrm{~s}, p>0.05$ ) and 24h (Fig. 13c).

The improvements by IL-10 treatment observed in the individual tests were reflected in the NDS (Fig. 13d). We observed a significant high score in mice treated with IL-10 at $3 \mathrm{~h}$ (GLU $3 \pm 2$ points and GLU + IL-10 $22 \pm 4$ points $p<0.05)$, which progressively improved and reached values similar to those observed in control group at $24 \mathrm{~h}$ (GLU $11 \pm 5$ points and GLU + IL-10 $40 \pm$ 3 points $p<0.05$; Fig. 13d). Mice injected only with glutamate also showed a progressive increase in the motor score, but it was significantly lower of the control values at all times.

\section{Discussion}

In ischemia and brain trauma, neurons lose the ability to control ion homeostasis minutes after the primary injury, resulting in the accumulation of intracellular calcium, cell depolarization, release of glutamate, impaired mitochondrial function, energy failure, and elevated reactive oxygen species production [57-59]. This occurs during the first few minutes-hours after the event and will determine the course of brain damage, including neuroinflammation. For example, the use of NMDA receptor blockers in experimental models of ischemia and 


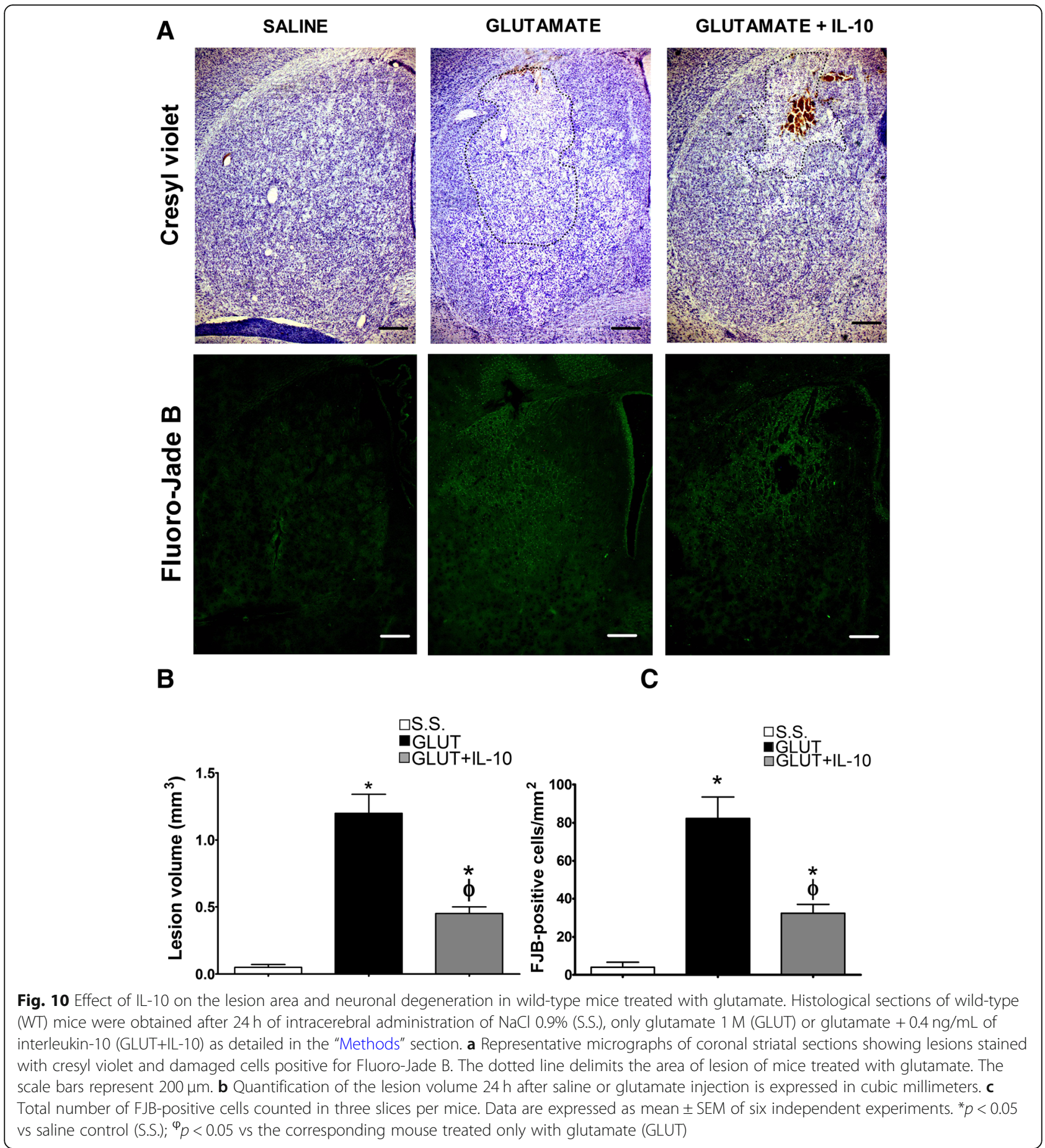

trauma markedly reduces neuronal damage and neuroinflammation when administered during the first minutes-hours of insult [60,61]. Diverse studies postulate that the magnitude of the primary response is associated with the severity of the inflammatory response that can last for months or even years [62, 63]. Therefore, it is necessary to evaluate the processes taking place during the early stages of brain injury, as we did in this study. This could help to define the early clinical intervention that can be decisive in the prognosis.

In animal models, the exogenous administration of glutamate produces an overstimulation of synaptic receptor that leads to oxidative stress and neuronal death. Besides, the excitotoxic damage is closely associated with an inflammatory response [64]. During this process, ROS are key pieces since they participate directly in 


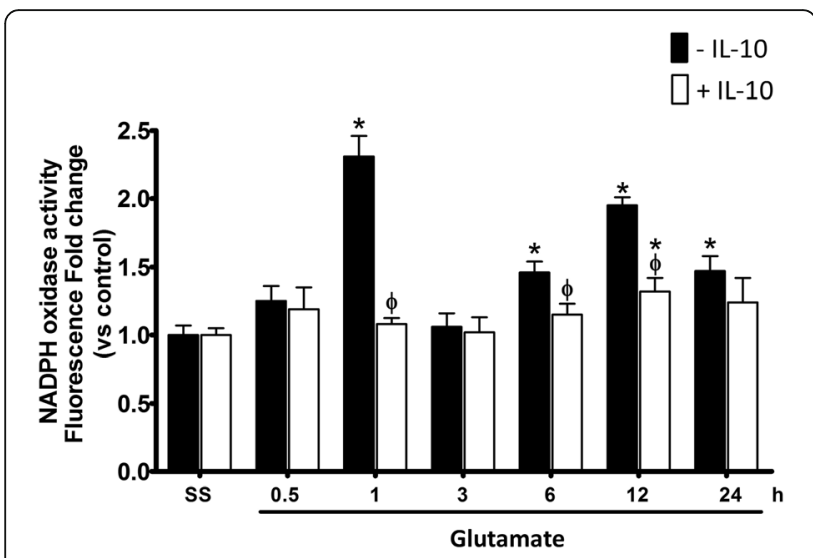

Fig. 11 NOX activity in wild-type mice treated with IL-10 after glutamate administration. NOX activity was evaluated in wild-type mice (WT) treated with $\mathrm{NaCl} 0.9 \%(S . S$.$) , only glutamate 1 \mathrm{M} \mathrm{(-} \mathrm{IL-10)} \mathrm{or}$ glutamate $+0.4 \mathrm{ng} / \mathrm{mL}$ of IL-10 (+ IL-10) as detailed in the "Methods" section. The determination of NOX activity was measured as the change in fluorescence intensity resulting from the dihydroethidium (DHE) oxidation to ethidium (Et) in striatal homogenates after 0.5, 1, 3, 6,12 , and $24 \mathrm{~h}$ after glutamate administration. Data are expressed as fold change of Et fluorescence relative to saline without IL-4. Values are means \pm SEM of three independent experiments. ${ }^{*} p<0.05$ vs the corresponding saline control; ${ }^{\varphi} p<0.05$ vs the corresponding time of mice treated with glutamate alone

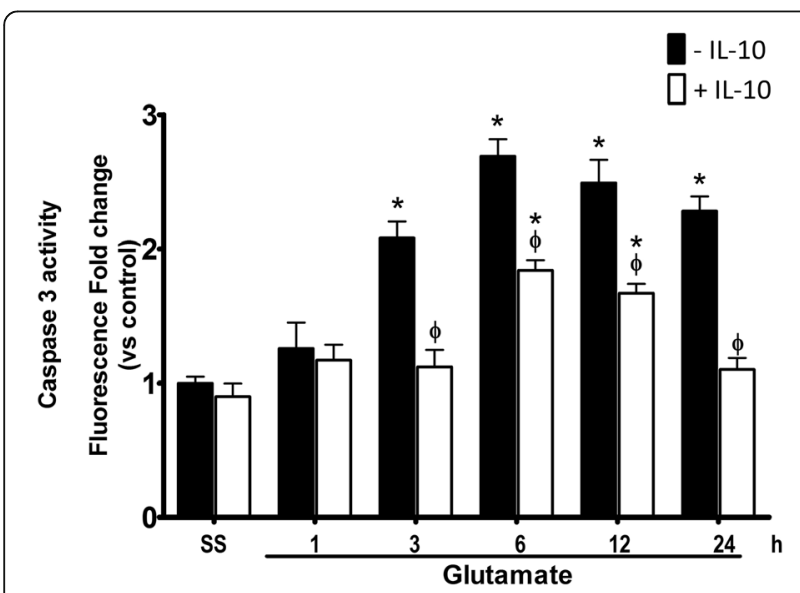

Fig. 12 Active caspase-3 in mice treated with IL-10 after glutamate administration. Active caspase-3 was measured in striatal homogenates of wild-type (WT) mice treated with $\mathrm{NaCl} 0.9 \%$ (S.S.), only glutamate 1 $\mathrm{M}(-\mathrm{IL}-10)$ or glutamate $+0.4 \mathrm{ng} / \mathrm{mL}$ of IL-10 (+ IL-10) at $1,3,6,12$, and $24 \mathrm{~h}$ after glutamate administration. Fluorescence produced by the cleavage of the specific substrate was quantified in relative units of fluorescence (FRU). Data are expressed as fold change of fluorescence relative to saline without IL-4. Values are means \pm SEM of three independent experiments. ${ }^{*} p<0.05$ vs the corresponding saline control; ${ }^{\varphi} p<0.05$ vs the corresponding time of mice treated with glutamate alone neuronal death and other parallel physiological processes that are also affected by the excitotoxicity [65, 66].

Several sources of cellular ROS have been involved in the excitotoxic damage; one of the most interesting is the NOX family, whose only known function is ROS production [64, 67]. The seven homologs (NOX-1 to NOX-5 and DUOX-1 and DUOX-2) have different subcellular localizations, and their activation is associated with various signaling pathways of the cell physiology $[25,48]$. Particularly, NOX-2 seem to be involved in cell death, since its inhibition markedly reduces neuronal damage in several pathological processes such as ischemia, hypoglycemia, and brain trauma $[8,9,14]$, where excitotoxicity is a main component.

In previous studies, we demonstrated that pharmacological inhibition of NOX in primary cultures of cerebellar granule neurons decreases apoptotic death caused by different conditions $[67,68]$. Using an animal model of genetic inhibition of NOX-2 or with the administration of NOX inhibitors, we have confirmed the involvement of NOX-2 in excitotoxic neuronal death [13], which correlated with findings of other groups that report that the increase of NOX-2 activity promotes apoptotic death [69].

In the present study, we corroborated that NOX-2 KO mice are less susceptible to excitotoxic damage than WT mice, evidenced by a smaller lesion and less number of positive cells to Fluoro-Jade $\mathrm{B}$ in NOX-2 $\mathrm{KO}$ mice treated with glutamate (Fig. 2). In this model, we corroborated that NOX-2 is involved in excitotoxic damage since an increase of NOX activity was observed in response to the administration of glutamate. This increase occurred in a biphasic manner ( 1 and $12 \mathrm{~h}$ after glutamate administration). Since both peaks of NOX activity occurred within $12 \mathrm{~h}$ of difference (Fig. 3), we suggest that this feature is part of two separate phenomena. We hypothesize that the first increase in ROS participates in a direct response to the extracellular increase of glutamate, while the increase observed at $12 \mathrm{~h}$ probably corresponds to the cellular response for the recovery of homeostasis; however, more studies are required to test this possibility.

Our results indicated that the lack of NOX-2 is associated with a minor activation of caspase-3 (Fig. 4), probably resulting from a decrease in apoptotic signaling pathways. It is likely that the neuroprotective effect observed in NOX-2 KO mice results from a decrease of the initial damage and reduced activation of subsequent death signaling pathways. These findings correlate with reports in showing that the increase of NOX-2 activity is associated with the activation of caspase- 3 and apoptotic death $[68,69]$. It is important to emphasize that the excitotoxic damage includes other mechanisms of cell death (necrosis and autophagy) and that the lack of NOX-2 activity does not completely prevent cell death. 

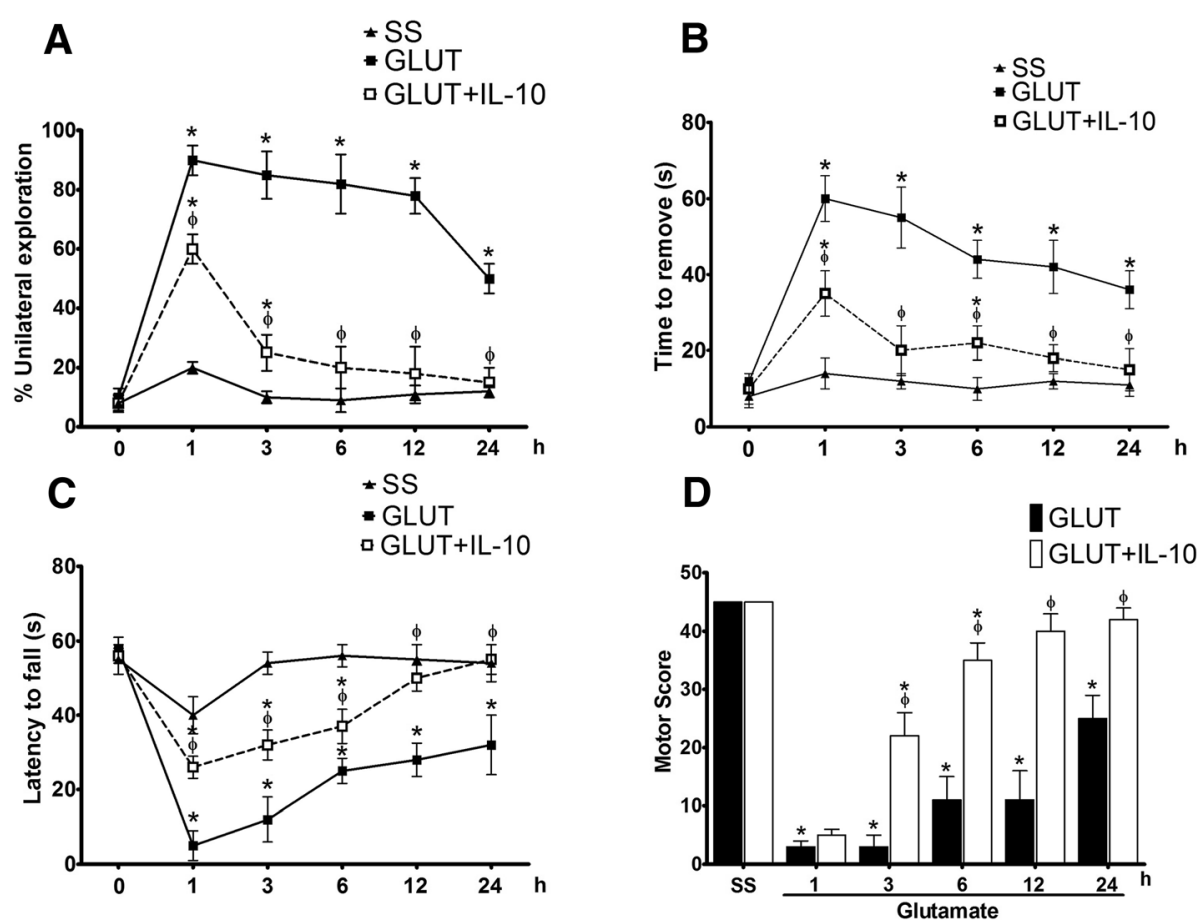

Fig. $13 \mathrm{LL}-10$ improves motor recovery in wild-type mice after glutamate administration. Motor behavior of wild-type mice injected with $\mathrm{NaCl}$ $0.9 \%$ (SS), 1 M glutamate (GLUT) and glutamate $+0.4 \mathrm{ng} / \mathrm{mL}$ of IL-10 (GLUT + IL-10), was evaluated in three tests of motor behavior at 1, 3, 6, 12, and $24 \mathrm{~h}$ after glutamate intracerebral injection. a Cylinder test, in which each mouse obtained a percentage based on the ratio of unilateral and bilateral explorations performed in three trials, of 3 min each; the percentage was expressed as mean \pm SEM of six independent tests. $\mathbf{b}$ Adhesive removal test quantifies the time in which the animals remove a label previously placed by the examiner. The time of removal was quantified in seconds and was expressed as means \pm SEM of six independent tests. c Inverted grid test was evaluated by exposing the mice to the inverted grid test in which the decay time was quantified for three non-consecutive opportunities of a maximum of $60 \mathrm{~s}$ of duration. The results are expressed as means \pm SEM of the latency to fall of six independent tests. $\mathbf{d}$ Integration of behavioral performance of three previous tests was carried out by assigned an arbitrary score to the performance of each animal, giving the highest score to the performance of the mice injected with saline (45 points). The results are expressed in arbitrary units of motor score as the mean \pm SEM of the latency to fall of six independent tests. ${ }^{*} p<0.05$ vs the corresponding saline control; ${ }^{\varphi} p<0.05$ vs corresponding mouse treated with glutamate alone

Striatal injuries usually result in impaired sensorimotor function and movement execution [70]. The present results show a clear positive correlation between a reduction of the lesion size and a better recovery of motor function. In both WT and NOX-2 KO mice treated with glutamate, the initial motor function was similarly affected, probably due to the action of glutamate on striatal neuronal circuits. However, this condition improves much faster for the NOX-2 KO animals (Fig. 5) according to the damage observed in both animals (Fig. 2).

The increase in NOX-2 activity is relevant for excitotoxic damage and the inflammatory process. It has been suggested that it contributes, along with various cytokines, to the function impairment and secondary damage orchestrated by microglia [71, 72]. Persistent inflammation can promote secondary tissue injury through excess production of proinflammatory factors, such as TNF- $\alpha$, IL-1 $\beta$, and IL-6. These factors promote the polarization of the resident microglia to the M1 phenotype, which in turn causes neuronal death; the sum of these events results in the aggravation of the initial injury and a poor resolution of damage.

In a previous study, we observed that during the excitotoxic damage, the activated microglia in NOX-2 KO mice showed different morphological characteristics as compared to WT animals [13]. In the present work, we observed that NOX-2 mice have a different profile of cytokines production. The major change in the pattern of cytokine production corresponded to the increase in anti-inflammatory cytokines such as IL-4, IL-10, and TGF- $\beta$, just a few hours after the initiation of the injury (Fig. 6).

As expected, we observed an increase in the production of IL-1 $\beta$ after 6 and $12 \mathrm{~h}$ of glutamate treatment. However, we did not observe any differences between the WT and NOX2-KO mice at any time after glutamate treatment (Fig. 6). This contrasts with the observed results in a model of TBI, where NOX2 deficiency induced a lower expression of IL-1 $\beta$ after the trauma [46]. In addition to NOX2, it has been suggested that mitochondrial ROS also play a key role in the inflammatory 
process through the NLRP3 inflammasome activation [73]. It is known that the production of IL- $1 \beta$ is regulated enzymatically by the NLRP3 inflammasome [74, 75 ] and a lower IL-1 $\beta$ secretion is observed in macrophages treated with mitochondrial ROS scavengers [42]. The NLRP3 inflammasome is stimulated by ROS [76], and NOX-derived ROS were initially suggested to be necessary for NLRP3 inflammasome activation [77]. However, in mouse macrophages deficient in NOX, IL- $1 \beta$ production is unaffected [78]. This observation suggests that the mechanisms involved in NLRP3 activation and IL-1 $\beta$ production are dependent on the source of ROS production and the type of insult. Possibly in the present experimental conditions, other sources of ROS rather than NOX are necessary for IL- $1 \beta$ production.

One of the most remarkable findings in this study is that in the NOX-2 KO mice, IL-4 production increases very early during the excitotoxic process, which correlates with previous reports, suggesting that IL-4 contributes to the polarization of the microglia to an M2 phenotype promoting an anti-inflammatory response. Recent evidence shows that neurons that survive a noxious stimulus (i.e., ischemia) respond by increasing the production and release of IL-4 [20]. Although the effects of IL-4 on neuronal survival have not been extensively described, it is known that its increase may promote the release of neurotrophic factors that favor axonal repair and neuronal survival.

The increase of IL-4 in NOX-2 KO mice suggests that NOX-2 participates in the negative regulation of this interleukin. This can directly influence the inflammatory response dynamics, since IL-4 contributes decisively to the acquisition of a microglial anti-inflammatory phenotype producer of IL-10. During excitotoxic damage, the increase of NOX-2 activity correlated temporarily with the decrease of anti-inflammatory cytokines and the increase in inflammatory mediators, which agrees with that reported by other groups who postulate that NOX regulates the production and release of anti-inflammatory cytokines [79, 80].

Similarly, the production of IL-10 is also markedly increased, probably induced by IL-4 [21]. The stimulation of IL-4R $\alpha$ microglial receptors promotes the activation of several signaling pathways, including the activation of Janus kinase 3/transcription 6 (JAK3/STAT6) and insulin receptor substrate 2 (IRS2). This situation promotes the expression of IL-10 by the nuclear factor kappa-light-chain-enhancer of activated B cells $(\mathrm{NF} \kappa \mathrm{B})$ and negatively regulates the production of inflammatory interleukins by the suppressor of cytokine signaling 1 (CS1) [80].

It is known that the binding of IL-10 to its neuronal receptors (IL-10R) activates the JAK2/STAT3 pathway, which reduces oxidative stress and promotes neuronal survival [81]. It is possible that part of the observed decrease in caspase- 3 activation and cell death in NOX-2 KO animals could be a consequence of a decreased ROS production, by activation of IL-10R during excitotoxicity.

In our model, a single intracerebral dose of recombinant IL-10 decreased caspase-3 activation in WT mice subjected to excitotoxic damage (Fig. 12), and it is important to note that the concentration of IL-10 administered was similar to that found in the NOX-2 KO mice subjected to the excitotoxic event. Our results showed that the treatment with IL-10 negatively regulates NOX activity (Fig. 11), which could also be associated with the reduction of oxidative stress and therefore less neuronal death.

Interestingly, in contrast to what we observed in NOX-2 KO mice (Fig. 4), the administration of IL-10 did not decrease active caspase- 3 induced by glutamate treatment in the initial phase ( 3 and $6 \mathrm{~h}$ ), but late in the process (12 and $24 \mathrm{~h}$ ) (Fig. 9). This suggests that IL-10 could promote neuronal survival only during the secondary phase, being the inflammatory process a probable target. This is in line with the finding that the administration of a single dose of IL-4 markedly reduced the lesion volume (Fig. 7), but the decrease in NOX activity (Fig. 8) and caspase-3 activity (Fig. 9) occurred after 12 and $24 \mathrm{~h}$ of glutamate administration.

Based on our findings, including the time course of the different parameters evaluated, we can delimit two phases in the progression of neuronal damage induced by glutamate administration: an initial response, from the onset of administration to the subsequent $6 \mathrm{~h}$ and a secondary response, from $6 \mathrm{~h}$ and up to $24 \mathrm{~h}$ post administration. In WT mice, the initial phase is characterized by an increase in NOX activity and IL-12 production, which promotes a proinflammatory state and severe motor deterioration. During the secondary response, a proinflammatory environment predominates (increased IL-1 $\beta$, IL- 6 , and TNF- $\alpha$ production and NOX activity), which promotes apoptotic neuronal death. In contrast, in NOX-2 KO mice, the initial response is characterized by an increased production of IL-4 and IL-10, which probably contributes to a decreased apoptotic death and an improved functional recovery.

Interestingly, when IL-4 was administered to WT mice treated with glutamate, NOX activity and caspase-3 activation were reduced only during the secondary response, probably because its effect depends on the increase of other factors. In support of this, when IL-10 was administered to these animals, NOX activity and caspase- 3 activation decreased in both the early and the late phase after glutamate administration.

Altogether, these results lead us to propose that the neuroprotection resulting from the genetic inhibition of NOX-2 could be due, at least partially, to a differential response to excitotoxic damage, which is characterized 
by an early increased production of anti-inflammatory cytokines. We have shown that the inhibition of NOX-2 activity facilitates the production of anti-inflammatory cytokines, which in turn decreases the injury secondary to excitotoxic damage and improves functional recovery.

\section{Conclusions}

The release of proinflammatory cytokines during the excitotoxic cascade promotes a secondary apoptotic death of neurons that survived the damage. During the excitotoxic process and the subsequent inflammatory response, ROS generated by NOX-2 play a decisive role in the extension of the lesion and consequently in the severity of the functional compromise.

We propose that the neuroprotection resulting from a lack of NOX-2 activity could be due, at least partially, to a differential response against excitotoxic damage, characterized by an increased production of anti-inflammatory cytokines. Although it is necessary to determine the exact mechanism by which NOX-2 participates in the regulation of these cytokines, we suggest that the inhibition of NOX-2 activity facilitates the production of IL-4, which contributes to the production of IL-10.

\section{Additional file}

Additional file 1: Figure S1. Expression of gp91 phox (NOX-2) in the striatum of wild-type and NOX-2 KO mice after glutamate treatment. (A) Levels of gp91phox (NOX-2) at 1, 6, 12, and $24 \mathrm{~h}$ after the intracerebral administration of glutamate $(1 \mathrm{M})$. The results are expressed as fold over the relative intensity in relation to the load control (GAPDH), against time in hours (h). Values represent the average \pm SEM of four independent tests. ${ }^{*} p<0.05$ vs the corresponding saline control. (B) Western blot of gp91 phox (band size $65 \mathrm{kDa}$ ) and GAPDH (band size $37 \mathrm{kDa}$ ) representative images. (TIF $121140 \mathrm{~kb}$ )

\section{Abbreviations \\ ANOVA: Analysis of variance; CNS: Central nervous system; \\ DHE: Dihydroethidium; DPI: Diphenyleneiodonium; DUOX: Dual oxidases; \\ ELISA: Enzyme-linked immunosorbent assay; Et: Ethidium; FJB: Fluoro-Jade B; GLU: Glutamate; IL: Interleukin; IL-R: Interleukin receptor; JAK: Janus kinase; NDS: Neurological dysfunction score; NOX: NADPH oxidases; NOX-2: NADPH oxidase-2; ROS: Reactive oxygen species; SEM: Standard error of the mean; SOD: Superoxide dismutase; TGF- $\beta$ : Transforming growth factor beta; TNF- a: Tumor necrosis factor-a; WT: Wild-type}

\section{Acknowledgements}

The authors are grateful to María Guadalupe Domínguez Macouzet for her excellent technical assistance. The authors thank Héctor Alfonso Malagón Rivero and Claudia V. Rivera Cerecedo for mice care at the Bioterio, as well as to Daniela Rodríguez for processing the tissue sections in the Histology Unit.

\section{Funding}

This work was supported by DGAPA-UNAM (IN210716 and IN212019) and CONACYT (285184). Diego R. Hernández Espinosa is a doctoral student from the Programa de Doctorado en Ciencias Biomédicas, Universidad Nacional Autónoma de México (UNAM), and he was a recipient of fellowship from CONACYT (290121).

\section{Availability of data and materials}

The datasets used and/or analyzed during the current study are available from the corresponding author on reasonable request.

\section{Authors' contributions}

DRHE carried out the work, data analysis, and the writing of the manuscript and participated in the design of the study. LM and TM contributed to the planning of the model and the revision of the data and the images. JM conceived the study and participated in the analysis of the data, the feedback, and the draft of the manuscript. All authors read and approved the final manuscript

\section{Ethics approval and consent to participate}

All animals were handled according to the National Institutes of Health Guide for the Care and Use of laboratory animals (NIH Publication No. 8023, revised 1978) and the local Committee for the Care and Use of Laboratory Animals (protocol JMA72-15).

\section{Consent for publication}

Not applicable

\section{Competing interests}

The authors declare that they have no competing interests.

\section{Publisher's Note}

Springer Nature remains neutral with regard to jurisdictional claims in published maps and institutional affiliations.

Received: 21 January 2019 Accepted: 3 April 2019

Published online: 17 April 2019

\section{References}

1. MacDermott AB, Mayer ML, Westbrook GL, Smith SJ, Barker JL. NMDAreceptor activation increases cytoplasmic calcium concentration in cultured spinal cord neurones. Nature. 1986;1986(321):519-22. https://doi.org/10. 1038/321519a0

2. Lai TW, Zhang S, Wang YT. Excitotoxicity and stroke: identifying novel targets for neuroprotection. Prog Neurobiol. 2014;115:157-88. https://doi. org/10.1016/j.pneurobio.2013.11.006.

3. Brown GC. Mechanisms of inflammatory neurodegeneration: iNOS and NADPH oxidase. Biochem. Soc. Trans. 2007;35(Pt 5):1119-21. https://doi.org/ 10.1042/BST0351119.

4. Cooney SJ, Zhao Y, Byrnes KR. Characterization of the expression and inflammatory activity of NADPH oxidase after spinal cord injury. Free Radic Res. 2014;48(8):929-39. https://doi.org/10.3109/10715762.2014.927578.

5. Hoffmann MH, Griffiths HR. The dual role of ROS in autoimmune and inflammatory diseases: evidence from preclinical models. Free Radic Biol Med. 2018;125:62-71. https://doi.org/10.1016/j.freeradbiomed.2018.03.016.

6. Nicholls DG, Johnson-Cadwell L, Vesce S, Jekabsons M, Yadava N. Bioenergetics of mitochondria in culured neurons and their role in glutamate excitotoxicity. J Neurosci Res. 2007;85(15):3206-12. https://doi. org/10.1002/jnr.21290.

7. Kahles T, Brandes RP. NADPH oxidases as therapeutic targets in ischemic stroke. Cell Mol Life Sci. 2012;69(14):2345-63. https://doi.org/10.1007/s00018012-1011-8.

8. Páramo B, Montiel T, Rivera-Martínez M, Morán J, Massieu L. Calpain activation induced by glucose deprivation is mediated by oxidative stress and contributes to neuronal damage. Int J Biochem Cell Biol. 2013;45(11): 2596-604. https://doi.org/10.1016/j.biocel.2013.08.013.

9. Hirano K, Chen WS, Chueng AL, Dunne AA, Seredenina T, Filippova A, Ramachandran S, Bridges A, Chaudry L, Pettman G, Allan C, Duncan S, Lee KC, Lim J, Ma MT, Ong AB, Ye NY, Nasir S, Mulyanidewi S, Aw CC, Oon PP, Liao S, Li D, Johns DG, Miller ND, Davies CH, Browne ER, Matsuoka Y, Chen DW, Jaquet V, Rutter AR. Discovery of GSK2795039, a novel small molecule NADPH oxidase 2 inhibitor. Antioxid Redox Signal. 2015;23(5):358-74. https://doi.org/10.1089/ars.2014.6202.

10. Ma MW, Wang J, Dhandapani KM, Brann DW. NADPH oxidase 2 regulates NLRP3 inflammasome activation in the brain after traumatic brain injury. Oxidative Med Cell Longev. 2017;2017:6057609. https://doi.org/10.1155/ 2017/6057609. 
11. Wang Z, Wei X, Liu K, Zhang X, Yang F, Zhang H, He Y, Zhu T, Li F, Shi W, Zhang Y, Xu H, Liu J, Yi F. NOX2 deficiency ameliorates cerebral injury through reduction of complexin II-mediated glutamate excitotoxicity in experimental stroke. Free Radic Biol Med. 2013;65:942-51. https://doi.org/10. 1016/j.freeradbiomed.2013.08.166.

12. Zhang L, Li Z, Feng D, Shen H, Tian X, Li H, Wang Z, Chen G. Involvement of Nox2 and Nox4 NADPH oxidases in early brain injury after subarachnoid hemorrhage. Free Radic Res. 2017;51(3):316-28. https://doi.org/10.1080/ 10715762.2017.1311015.

13. Guemez-Gamboa A, Estrada-Sánchez AM, Montiel T, Páramo B, Massieu L, Morán J. Activation of NOX2 by the stimulation of ionotropic and metabotropic glutamate receptors contributes to glutamate neurotoxicity in vivo through the production of reactive oxygen species and calpain activation. J Neuropathol Exp Neurol. 2011;70(11):1020-35. https://doi.org/ 10.1097/NEN.0b013e3182358e4e.

14. Chandran R, Kim T, Mehta SL, Udho E, Chanana V, Cengiz P, Kim H, Kim C, Vemuganti R. A combination antioxidant therapy to inhibit NOX2 and activate Nrf2 decreases secondary brain damage and improves functional recovery after traumatic brain injury. J Cereb Blood Flow Metab. 2017: 271678X17738701. https://doi.org/10.1177/0271678X17738701.

15. Lyman M, Lloyd DG, Ji X, Vizcaychipi MP, Ma D. Neuroinflammation: the role and consequences. Neurosci Res. 2014;79:1-12. https://doi.org/10.1016/j. neures.2013.10.004.

16. Hong H, Kim BS, Im HI. Pathophysiological role of neuroinflammation in neurodegenerative diseases and psychiatric disorders. Int Neurourol J. 2016; 20(Suppl 1):S2-7. https://doi.org/10.5213/inj.1632604.302.

17. Vinet J, Weering HR, Heinrich A, Kälin RE, Wegner A, Brouwer N, Heppner FL, Rooijen N, Boddeke HW, Biber K. Neuroprotective function for ramified microglia in hippocampal excitotoxicity. J Neuroinflammation. 2012;9:27. https://doi.org/10.1186/1742-2094-9-27.

18. Kreutzberg GW. Microglia: a sensor for pathological events in the CNS Trends Neurosci. 1996;19(8):312-8 https://doi.org/10.1016/01662236(96)10049-7.

19. Nakajima M, Nito C, Sowa $K$, Suda S, Nishiyama $Y$, Nakamura-Takahashi A, Nitahara-Kasahara Y, Imagawa K, Hirato T, Ueda M, Kimura K, Okada T. Mesenchymal stem cells overexpressing interleukin-10 promote neuroprotection in experimental acute ischemic stroke. Mol Ther Methods Clin Dev. 2017:6:102-11. https://doi.org/10.1016/j.omtm.2017.06.005.

20. Kim DW, Lee JC, Cho JH, Park JH, Ahn JH, Chen BH, Shin BN, Tae HJ, Seo JY, Cho JH, Kang IJ, Hong S, Kim YM, Won MH, Kim IH. Neuroprotection of ischemic preconditioning is mediated by anti-inflammatory, not proinflammatory, cytokines in the gerbil hippocampus induced by a subsequent lethal transient cerebral ischemia. Neurochem. Res. 2015;40(9): 1984-95. https://doi.org/10.1007/s1 1064-015-1694-y.

21. Lobo-Silva D, Carriche GM, Castro AG, Roque S, Saraiva M. Balancing the immune response in the brain: $I L-10$ and its regulation. J Neuroinflammation. 2016;13(1):297. https://doi.org/10.1186/s12974-0160763-8.

22. Dinarello C. Historical review of cytokines. Eur J Immunol. 2007;37(Suppl 1): S34-45. https://doi.org/10.1002/eji.200737772.

23. Patel RK, Prasad N, Kuwar R, Haldar D, Abdul-Muneer PM. Transforming growth factor-beta 1 signaling regulates neuroinflammation and apoptosis in mild traumatic brain injury. Brain Behav Immun. 2017;64:244-58. https:// doi.org/10.1016/j.bbi.2017.04.012.

24. Dong $Y$, Kalueff AV, Song C. N-methyl-d-aspartate receptor-mediated calcium overload and endoplasmic reticulum stress are involved in interleukin-1beta-induced neuronal apoptosis in rat hippocampus. J Neuroimmunol. 2017;307:7-13. https://doi.org/10.1016/j.jneuroim.2017. 03.005 .

25. Dai $Y$, Zhang $H$, Zhang J, Yan M. Isoquercetin attenuates oxidative stress and neuronal apoptosis after ischemia/reperfusion injury via Nrf2-mediated inhibition of the NOX4/ROS/NF-kB pathway. Chem Biol Interact. 2018;284: 32-40. https://doi.org/10.1016/j.cbi.2018.02.017.

26. Park KW, Lee DY, Joe EH, Kim SU, Jin BK. Neuroprotective role of microglia expressing interleukin-4. J Neurosci Res. 2005;81(3):397-402. https://doi.org/ 10.1002/jnr.20483.

27. Garcia JM, Stillings SA, Leclerc J, Phillips H, Edwards NJ, Robicsek S, Hoh BL, Blackburn S, Doré S. Role of interleukin-10 in acute brain injuries. Front Neurol. 2017:8:244. https://doi.org/10.3389/fneur.2017.00244

28. Mills CD, Kincaid K, Alt JM, Heilman MJ, Hill AM. M-1/M-2 macrophages and the Th1/Th2 paradigm. J Immunol. 2000;164(12):6166-73.
29. Mikita J, Dubourdieu-Cassagno N, Deloire MS, Vekris A, Biran M, Raffard G, Brochet B, Canron MH, Franconi JM, Boiziau C, Petry KG. Altered M1/M2 activation patterns of monocytes in severe relapsing experimental rat model of multiple sclerosis. Amelioration of clinical status by $\mathrm{M} 2$ activated monocyte administration. Mult Scler. 2011;17(1):2-15. https://doi.org/10. 1177/1352458510379243.

30. Loke P, Nair MG, Parkinson J, Guiliano D, Blaxter M, Allen JE. IL-4 dependent alternatively-activated macrophages have a distinctive in vivo gene expression phenotype. BMC Immunol. 2002;3:7.

31. Xia CY, Zhang S, Gao Y, Wang ZZ, Chen NH. Selective modulation of microglia polarization to M2 phenotype for stroke treatment. Int Immunopharmacol. 2015;25(2):377-82. https://doi.org/10.1016/j.intimp.2015. 02.019 .

32. Gordon S, Martinez FO. Alternative activation of macrophages: mechanism and functions. Immunity. 2010;32(5):593-604. https://doi.org/10.1016/j. immuni.2010.05.007.

33. Morganti JM, Riparip LK, Rosi. Call off the dog(ma): M1/M2 polarization is concurrent following traumatic brain injury. PLoS One. 2016;11(1):e0148001. https://doi.org/10.1371/journal.pone.0148001.

34. Edwards JP, Zhang X, Frauwirth KA, Mosser DM. Biochemical and functional characterization of three activated macrophage populations. J Leukoc Biol. 2006;80(6):1298-307

35. Franco R, Fernández-Suárez D. Alternatively, activated microglia and macrophages in the central nervous system. Prog Neurobiol. 2015;131:6586. https://doi.org/10.1016/j.pneurobio.2015.05.003.

36. Ransohoff RM. A polarizing question: do $\mathrm{M} 1$ and $\mathrm{M} 2$ microglia exist? Nat Neurosci. 2016;19(8):987-91. https://doi.org/10.1038/nn.4338.

37. Mosser DM, Edwards JP. Exploring the full spectrum of macrophage activation. Nat Rev Immunol. 2008;8(12):958-69. https://doi.org/10.1038/ nri2448.

38. Chhor V, Le Charpentier T, Lebon S, Ore M, Celador I, Josserand J, Degos V, Jacotot E, Hagberg H, Savman K, Mallard C, Gressens P, Fleiss B. Characterization of phenotype markers and neuronotoxic potential of polarized primary microglia in vitro. Brain Behav Immun. 2013;32:70-85. https://doi.org/10.1016/j.bbi.2013.02.005.

39. Sironi M, Martinez FO, D'Ambrosio D, Gattorno M, Polentarutti N, Locati M, Gregorio A, lellem A, Cassatella MA, Van Damme J, Sozzani S, Martini A, Sinigaglia F, Vecchi A, Mantovani A. Differential regulation of chemokine production by Fcgamma receptor engagement in human monocytes: association of CCL1 with a distinct form of M2 monocyte activation (M2b, type 2). J Leukoc Biol. 2006;80(2):342-9.

40. Liao B, Zhao W, Beers DR, Henkel JS, Appel SH. Transformation from a neuroprotective to a neurotoxic microglial phenotype in a mouse model of ALS. Exp Neurol. 2012;237(1):147-52. https://doi.org/10.1016/j.expneurol. 2012.06.011.

41. Qin L, Liu Y, Wang T, Wei SJ, Block ML, Wilson B, Liu B, Hong JS. NADPH oxidase mediates lipopolysaccharide-induced neurotoxicity and proinflammatory gene expression in activated microglia. J Biol Chem. 2004; 279(2):1415-21. https://doi.org/10.1074/jbc.M307657200.

42. Brüne B, Dehne N, Grossmann N, Jung M, Namgaladze D, Schmid T, von Knethen A, Weigert A. Redox control of inflammation in macrophages. Antioxid Redox Signal. 2013;19(6):595-637. https://doi.org/ 10.1089/ars.2012.4785.

43. Rojo Al, McBean G, Cindric M, Egea J, López MG, Rada P, Zarkovic N, Cuadrado A. Redox control of microglial function: molecular mechanisms and functional significance. Antioxid Redox Signal. 2014;21(12):1766-801. https://doi.org/10.1089/ars.2013.5745.

44. Mander P, Brown GC. Activation of microglial NADPH oxidase is synergistic with glial iNOS expression in inducing neuronal death: a dual-key mechanism of inflammatory neurodegeneration. J Neuroinflammation. 2005;2:20. https://doi.org/10.1186/1742-2094-2-20.

45. Lee SH, Suk K. Identification of glia phenotype modulators based on select glial function regulatory signaling pathways. Expert Opin Drug Discov. 2018; 13(7):627-41. https://doi.org/10.1080/17460441.2018.1465925.

46. Pawate $S$, Shen $Q$, Fan F, Bhat NR. Redox regulation of glial inflammatory response to lipopolysaccharide and interferon gamma. J Neurosci Res. 2004; 77(4):540-51. https://doi.org/10.1002/jnr.20180

47. Kumar A, Barrett JP, Alvarez-Croda DM, Stoica BA, Faden Al, Loane DJ. NOX2 drives M1-like microglial/macrophage activation and neurodegeneration following experimental traumatic brain injury. Brain Behav Immun. 2016;58: 291-309. https://doi.org/10.1016/j.bbi.2016.07.158. 
48. Padgett LE, Burg AR, Lei W, Tse HM. Loss of NADPH oxidase-derived superoxide skews macrophage phenotypes to delay type 1 diabetes. Diabetes. 2015;64(3):937-46. https://doi.org/10.2337/db14-0929.

49. Estrada-Sánchez AM, Montiel T, Segovia J. Glutamate toxicity in the R6/2 Huntington's disease transgenic mice is age-dependent and correlates with decreased levels of glutamate transporters. Neurobiol Dis. 2009;34:78-86. https://doi.org/10.1016/j.nbd.2008.12.017.

50. Schmidt E, Morello F, Pasterkamp R. Dissection and culture of mouse dopaminergic and striatal explants in three-dimensional collagen matrix assays. J Vis Exp. 2012;61:3691. https://doi.org/10.3791/3691.

51. Liu X, Miller B, Rebec G, David E. Protein expression in the striatum and cortex regions of the brain for a mouse model of Huntington's disease. J Proteome Res. 2007;6(8):3134-42. https://doi.org/10.1021/pr070092s.

52. Thornberry NA, Rano TA, Peterson EP, Rasper DM, Timkey T, Garcia-Calvo M. A combinatorial approach defines specificities of members of the caspase family and granzyme B. functional relationships established for key mediators of apoptosis. J Biol Chem. 1997;272:17907-11.

53. Fleming SM, Zhu C, Fernagut PO, Mehta A, DiCarlo CD, Seaman RL, Chesselet MF. Behavioral and immunohistochemical effects of chronic intravenous and subcutaneous infusions of varying doses of rotenone. Exp Neurol. 2004;187:418-29. https://doi.org/10.1016/j.expneurol.2004.01.023.

54. Bouet V, Boulouard M, Toutain J, Divoux D, Bernaudin M, Schumann-Bard P, Freret $\mathrm{T}$. The adhesive removal test: a sensitive method to assess sensorimotor deficits in mice. Nat Protoc. 2009;4(10):1560-4. https://doi.org/ 10.1038/nprot.2009.125.

55. Wells J, Biernaskie J, Szymanska A, Larsen P, Yong WW, Corbett D. Matrix metalloproteinase (MMP)-12 expression has a negative impact on sensorimotor function following intracerebral hemorrhage in mice. Eur J Neurosci. 2005;21(1):187-96. https://doi.org/10.1111/j.1460-9568.2004.03829.

56. Barrett JP, Henry RJ, Villapol S, Stoica BA, Kumar A, Burns MP, Faden Al, Loane DJ. NOX2 deficiency alters macrophage phenotype through an IL-10/STAT3 dependent mechanism: implications for traumatic brain injury. J Neuroinflammation. 2017;14(1):65. https://doi.org/10.1186/s12974-017-0843-4.

57. Satoh M, Fujimoto S, Haruna Y. NAD(P)H oxidase and uncoupled nitric oxide synthase are major sources of glomerular superoxide in rats with experimental diabetic nephropathy. Am J Physiol Renal Physiol. 2005;288: F1144-52. https://doi.org/10.1152/ajprenal.00221.2004.

58. Zhao X, Zhang Y, Strong R, James C, Grotta A, Jaroslaw A. 15d-Prostaglandin $J(2)$ activates peroxisome proliferator-activated receptor-gamma, promotes expression of catalase, and reduces inflammation, behavioral dysfunction, and neuronal loss after intracerebral hemorrhage in rats. J Cereb Blood Flow Metab. 2006;26. https://doi.org/10.1038/sj.jcbfm.9600233.

59. Guerriero R, Giza C, Rotenberg A. Glutamate and GABA imbalance following traumatic brain injury. Curr Neurol Neurosci Rep. 2015;15:27. https://doi.org/ 10.1007/s11910-015-0545-1.

60. Hill R, Singh I, Wang J, Hall E. Time courses of post-injury mitochondrial oxidative damage and respiratory dysfunction and neuronal cytoskeletal degradation in a rat model of focal traumatic brain injury. Neurochem Int. 2017;111:45-56. https://doi.org/10.1016/j.neuint.2017.03.015.

61. Hinson $\mathrm{H}$, Rowell S, Schreiber M. Clinical evidence of inflammation driving secondary brain injury: a systematic review. J Trauma Acute Care Surg. 2015; 78:184-91. https://doi.org/10.1097/TA.0000000000000468.

62. Diaz-Arrastia R, Kochanek P, Bergold P, Kenney K, Marx C, Grimes C. Pharmacotherapy of traumatic brain injury: state of the science and the road forward: report of the department of defense neurotrauma pharmacology workgroup. J Neurotrauma. 2014;31:135-58. https://doi.org/ 10.1089/neu.2013.301.

63. Rich M, Keene C, Neher M, Johnson K, Yu Z, Ganivet A, Holers V, Stahel P. Site-targeted complement inhibition by a complement receptor 2conjugated inhibitor (mTT30) ameliorates post-injury neuropathology in mouse brains. Neurosci Lett. 2016;617:188-94. https://doi.org/10.1016/j. neulet.2016.02.025

64. Maycotte P, Guemez-Gamboa A, Moran J. Apoptosis and autophagy in rat cerebellar granule neuron death: role of reactive oxygen species. J Neurosci Res. 2010;88(1):73-85. https://doi.org/10.1002/jnr.22168.

65. Batlle M, Ferri L, Andrade C, Ortega F, Vidal-Taboada J, Pugliese M, Mahy N, Rodríguez M. Astroglia-microglia cross talk during neurodegeneration in the rat hippocampus. Biomed Res Int. 2015;2015:102419. https://doi.org/10. 1155/2015/102419

66. Choi HS, Park JH, Ahn JH, Hong S, Cho JH, Won MH, Lee $\mathrm{CH}$. The antiinflammatory activity of duloxetine, a serotonin/norepinephrine reuptake inhibitor, prevents kainic acid-induced hippocampal neuronal death in mice. J Neurol Sci. 2015;358(1-2):390-7. https://doi.org/10.1016/j.jns.2015 10.001 .

67. Coyoy A, Valencia A, Guemez-Gamboa A, Morán J. Role of NADPH oxidase in the apoptotic death of cultured cerebellar granule neurons. Free Radic Biol Med. 2008;45(8):1056-64. https://doi.org/10.1016/j.freeradbiomed.2008. 06.027.

68. Guemez-Gamboa A, Morán J. NOX2 mediates apoptotic death induced by staurosporine but not by potassium deprivation in cerebellar granule neurons. J Neurosci Res. 2009;87(11):2531-40. https://doi.org/10.1002/jnr. 22079.

69. Altenhöfer S, Kleikers PW, Radermacher KA, Scheurer P, Rob Hermans J, Schiffers $\mathrm{P}, \mathrm{Ho} \mathrm{H}$, Wingler $\mathrm{K}$, Schmidt $\mathrm{HH}$. The NOX toolbox: validating the role of NADPH oxidases in physiology and disease. Cell Mol Life Sci. 2012; 69(14):2327-43. https://doi.org/10.1007/s00018-012-1010-9.

70. Gensel JC, Zhang B. Macrophage activation and its role in repair and pathology after spinal cord injury. Brain Res. 2015;1619:1-11. https://doi.org/ 10.1016/j.brainres.2014.12.045.

71. Pepe G, De Maglie M, Minoli L, Villa A, Maggi A, Vegeto E. Selective proliferative response of microglia to alternative polarization signals. J Neuroinflammation. 2017;14(1):236. https://doi.org/10.1186/s12974-0171011-6.

72. Lawrence CB, Allan SM, Rothwell NJ. Interleukin-1 beta and the interleukin-1 receptor antagonist act in the striatum to modify excitotoxic brain damage in the rat. Eur J Neurosci. 1998;10(3):1188-95.

73. Meissner F, Seger RA, Moshous D, Fischer A, Reichenbach J, Zychlinsky A. Inflammasome activation in NADPH oxidase defective mononuclear phagocytes from patients with chronic granulomatous disease. Blood. 2010; 116(9):1570-3. https://doi.org/10.1182/blood-2010-01-264218.

74. Heid ME, Keyel PA, Kamga C, Shiva S, Watkins SC, Salter RD. Mitochondrial reactive oxygen species induces NLRP3-dependent lysosomal damage and inflammasome activation. J Immunol. 2013;191(10):5230-8. https://doi.org/ 10.4049/jimmunol.1301490.

75. Dostert C, Pétrilli V, Van Bruggen R, Steele C, Mossman BT, Tschopp J. Innate immune activation through Nalp3 inflammasome sensing of asbestos and silica. Science. 2008;320(5876):674-7. https://doi.org/10.1126/science. 1156995.

76. Codolo G, Plotegher N, Pozzobon T, Brucale M, Tessari I, Bubacco L, de Bernard M. Triggering of inflammasome by aggregated a-synuclein, an inflammatory response in synucleinopathies. PLoS One. 2013;8(1):e55375. https://doi.org/10.1371/journal.pone.0055375.

77. Hornung V, Bauernfeind F, Halle A, Samstad EO, Kono H, Rock KL, Fitzgerald KA, Latz E. Silica crystals and aluminum salts activate the NALP3 inflammasome through phagosomal destabilization. Nat Immunol. 2008;9(8): 847-56. https://doi.org/10.1038/ni.1631.

78. Pal R, Bajaj L, Sharma J, Palmieri M, Di Ronza A, Lotfi P, Chaudhury A, Neilson J, Sardiello M, Rodney GG. NADPH oxidase promotes Parkinsonian phenotypes by impairing autophagic flux in an mTORC1-independent fashion in a cellular model of Parkinson's disease. Sci Rep. 2016;6:22866. https://doi.org/10.1038/srep22866.

79. Lou Z, Wang AP, Duan XM, Hu GH, Song GL, Zuo ML, Yang ZB. Upregulation of NOX 2 and NOX4 mediated by TGF- $\beta$ signaling pathway exacerbates cerebral ischemia/reperfusion oxidative stress injury. Cell Physiol Biochem. 2018:46(5):2103-13. https://doi.org/10.1159/000489450.

80. Ferreira R, Lively S, Schlichter LC. IL-4 type 1 receptor signaling up-regulates KCNN4 expression and increases the KCa3.1 current and its contribution to migration of alternative-activated microglia. Front Cell Neurosci. 2014;8:183. https://doi.org/10.3389/fncel.2014.00183.

81. Zhu Y, Liu Z, Peng YP, Qiu YH. Interleukin-10 inhibits neuroinflammationmediated apoptosis of ventral mesencephalic neurons via JAK-STAT3 pathway. Int Immunopharmacol. 2017:50:353-60. https://doi.org/10.1016/j. intimp.2017.07.017. 